\title{
Matematik Öğretmenlerinin Zihin Tipleri ile Bilgisayarca Düşünme Becerileri
}

\section{Arasındaki İlişki}

Yeliz ÖZKAN HIDIROĞLU*, Çağlar Naci HIDIROĞLU**

• Geliş Tarihi: 29.02.2020• Kabul Tarihi: 17.12.2020 • Çevrimiçi Yayın Tarihi:

30.12 .2020

\section{Öz}

Çalışmanın amacı, matematik öğretmenlerinin geleceği şekillendirecek zihin tipleri ile bilgisayarca düşünme becerileri arasındaki ilişkiyi açıklamaktır. Araştırma nicel-ilişkisel tarama modeli çalışmasıdır. Bu çalışma seçkisiz örnekleme yöntemine göre seçilmiş ve gönüllü 481 matematik öğretmeni ile gerçekleştirilmiştir. Araştırmada veri toplama aracı olarak "Bilgisayarca Düşünme Becerileri Ölçeği” ve "Zihin Tipleri Ölçeği” kullanılmıştır. Verilerin analizinde betimsel istatistik, korelasyon ve regresyon analizinden yararlanılmıştır. Matematik öğretmenlerinin algılarına göre sahip oldukları etik zihin ve bilgisayarca düşünme becerileri "çok yüksek"; disiplinli zihin, sentezci zihin, yaratıcı zihin, saygılı zihin ve beşli zihin düzeyleri yüksektir. Matematik öğretmenlerinin algılarına göre sahip oldukları beşli zihinleri ile bilgisayarca düşünme becerileri arasında pozitif yönde yüksek düzeyde anlamlı bir ilişki vardır ve sahip oldukları beşli zihinler (hem boyut hem de bütün yapıda) bilgisayarca düşünmenin anlamlı bir yordayıcısıdır.

Anahtar Sözcükler: Bilgisayarca düşünme, geleceği şekillendirecek beş zihin, matematik öğretmeni.

Atıf:

Özkan-Hıdıroğlu, Y. ve Hıdıroğlu, Ç. N. (2021). Matematik öğretmenlerinin zihin tipleri ile bilgisayarca düşünme becerileri arasındaki ilişki. Pamukkale Üniversitesi Eğitim Fakültesi Dergisi, 52, 301-325.doi:10.9779/pauefd.696511

\footnotetext{
* Matematik Öğretmeni, Millî Eğitim Bakanlığı, Türkiye, yelizozkan09@gmail.com, ORCID ID: https://orcid.org/00000002-5176-1235

** Sorumlu Yazar, Doçent, Pamukkale Üniversitesi Matematik Eğitimi Anabilim Dalı, Denizli, Türkiye, chidiroglu@pau.edu.tr, ORCID ID: https://orcid.org/0000-0002-3774-4957
} 


\section{Giriş}

Bilimsel gelişmeler, toplumların bilgi ve beceri düzeyini yükselttiği gibi onların teknolojide ve dolayısıyla ekonomik anlamda güç kazanmalarını sağlamaktadır. Güçlü bir toplum olmak isteyen ülkeler ekonomik güce ulaşabilmek için, teknolojilerinin gelişmesi gerektiğini ve bunun bilimsel gelişmelerle olacağını bilerek hareket etmektedirler. Günümüzdeki ekonomik kalkınma, bilim ve teknoloji arasındaki bu etkileşime doğrudan bağlıdır. Bu anlayışa sahip ülkelerin en önemli amaçlarından biri, verecekleri nitelikli eğitimle bilim ve teknolojide becerikli ve öncü bireyler yetiştirmek olmaktadır.

Alanyazın incelendiğinde, 21. yüzyılda öğrenci ve öğretmen yeterliklerini geliştirmeye yönelik farklı öğrenme yaklaşımlarıyla karşılaşılmaktadır. Ülkelerin bilimsel ve teknolojik anlamda gelişmelerinin sağlanması için eğitimde Wing' in (2006) ön plana çıkardığı bilgisayarca düşünme (computational thinking) becerisi ve Gardner'ın (2006) geleceği şekillendirecek beş zihni iki önemli kuramsal çerçevedir.

\section{Eğitimde Bilgisayarca Düşünme}

Alanyazında "computational thinking" kavramının Türkçe olarak bilgisayarca düşünme (Çatlak, Tekdal ve Baz, 2015; Korkmaz, Çakır, \& Özden, 2016; Özden, 2015); bilgisayımsal düşünme (Çınar ve Tüzün, 2017; Doğan, Çınar, Bilgiç ve Tüzün, 2015); bilgi işlemsel düşünme (Çetin ve Toluk Uçar, 2017; Kalelioğlu ve Gülbahar, 2015); bilişimsel düşünme (Özkeş, 2016; Sayın ve Seferoğlu, 2016); kompütasyonel düşünme (Aldağ ve Tekdal, 2015; Şahiner ve Kert, 2016) ve hesaplamalı düşünme (Özçınar, 2017; Yecan, Özçınar ve Tanyeri, 2017) gibi farklı şekillerde ifade edildiği görülmektedir. Piaget'in ifade ettiği gibi aslında bir kavramın isimlendirilmesinden çok o kavramın nasıl algılandığı (zihinsel şema) daha önemlidir. Yazarlar bu adlandırmaların her birine eşit derecede yakın olsa da araştırmada hem Korkmaz ve diğerlerinin (2016) hazırladıkları "Bilgisayarca Düşünme Becerileri Ölçeği" kullanıldığı için hem de çalışma içerisinde bir dil birliği sağlanması için "bilgisayarca düşünme” ifadesinin kullanılmasına karar vermiştir.

İlk olarak Seymour Papert tarafından 1980 yılında ifade edilen bilgisayarca düşünme kavramını günümüzde eğitim alanyazınında öne çıkaran Wing (2006), bilgisayarca düşünmenin 21. yüzyılda yalnızca bilgisayar uzmanları için değil herkes için gerekli bir beceri olduğunu ifade etmektedir. Wing'e (2006) göre bilgisayarca düşünme; eleştirel düşünme, algoritmik düşünme, yaratıcılık ve işbirlikli öğrenmenin yanında problemlerin çözümünde gerekli olan dijital araçları kullanma yöntemlerini ve bunların hayata yansıtılmasını 
Y, Hıdıroğlu ve Ç. N, Hıdıroğlu/Pamukkale Üniversitesi Eğitim Fakültesi Dergisi, 52, 301-325, 2021303 içermektedir. Uluslararası Eğitim Teknolojileri Topluluğu [The International Society for Technology, ISTE] (2015) okuma, yazma ve aritmetik işlemler gibi çocukların tümünün sahip olması gereken becerilere bir çeşit analitik düşünme olan bilgisayarca düşünmenin de dâhil edilmesi gerektiğini ifade etmektedir. Gotlieb ve Borodin (1973) bilgisayar bilimlerindeki yöntemlerin sadece bilgisayar yazılımları veya donanımlarını geliştirme aracı olmasından ziyade tüm uygulama alanlarında yararlı olduğunu ve 21. yüzyılda bilgisayar biliminin tüm alanlara entegrasyonunun okuma, yazma ve aritmetik gibi küçük yaşlardan başlayarak öğrenilecek temel bir beceri haline geleceğini belirtmektedirler.

Farklı araştırmacılar bilgisayarca düşünmeyi farklı şekillerde tanımlamışlardır. Mannila, Dagiene, Demo, Grgurina, Mirolo, Rolandsson ve Settle'ye (2014) göre bilgisayarca düşünme, farklı disiplinlerdeki problemleri formülleştirmek ve çözüm üretmek için bilgisayar bilimindeki kavramları ve süreçleri kullanmaktır. Thomas, Odemwingie, Saunders ve Watlerd (2015) bilgisayarca düşünmeyi bir problemi tanımlama, anlama ve problemin çözümüne ilişkin algoritmaları ortaya koyma süreçleri olarak açıklamaktadır. Riley ve Hunt (2014) bilişsel süreçlere vurgu yaparak bilgisayarca düşünmeyi, bilgisayar bilimcileri gibi düşünme ve sorgulama yapma olarak ifade etmektedir. Y1ldız Durak ve Sarıtepeci (2018) bilgisayarca düşünmenin özelliklerini; bilgisayar kullanarak problemi formüle etme, bilgiyi mantıksal olarak organize ve analiz etme, bilgiyi model veya simülasyonlarla görselleştirme, algoritmik düşünme ile problemi otomatikleştirme, etkili ve daha etkili sonuçlar için olası çözümleri ortaya koyma, gerekli kaynakları ve adımları belirleme, problem çıktılarını genelleme ve farklı durumlara transfer etme şeklinde açıklamaktadır.

Bilgisayarca düşünmeye ilişkin sınıflandırmalar incelendiğinde; Lee, Martin, Denner, Coulter, Allan, Ericsson ve Werner (2011) bilgisayarca düşünmeyi soyutlama ve otomasyon; Barr ve Stephenson (2011) soyutlama, algoritma-prosedürler, otomasyon, problemi ayrıştırma, paralel işleme ve simülasyon; Angeli, Voogt, Fluck, Webb, Cox, Malyn-Smith ve Zagami, (2016) ise soyutlama, algoritma, ayrıştırma, hata ayıklama, genelleştirme olarak ele almaktadır. Weintrop, Beheshti, Horn, Orton, Jona, Trouille ve Wilensky (2014) tarafindan bilgisayarca düşünmenin dört alt başlık olarak ele alındığı görülmektedir. Bunlar; veri ve bilgi becerileri (veri toplama, veri oluşturma, verileri manipüle etme, verileri analiz etme ve verileri görselleştirme), modelleme ve simülasyon becerileri (bir kavramı anlamak için bilgisayarca modelleri kullanma, bilgisayarca modellerin nasıl ve neden çalıştığını anlama, bilgisayarca modelleri değerlendirme, çözümleri bulmak ve test etmek için bilgisayarca modelleri kullanma, yeni modeller oluşturma ve var olan modelleri genişletme); bilgisayarca problem 
çözme becerileri (hataları yakalama ve ayıklama, programlama, etkili bilgisayarca araçlar seçme, bir problem için farklı yaklaşımları/ çözümleri ölçme, modüler bilgisayarca çözümler geliştirme, problem çözme stratejilerini kullanma ve soyutlamalar yaratma) ve sistem yönetimi becerileri (bir sistemi bir bütün olarak inceleme, bir sistem içerisindeki ilişkileri anlama, seviyelerde düşünmek ve sistemleri görselleştirme, karmaşayı tanımlama, anlama ve yönetme)dir. Kalelioğlu, Gülbahar ve Kukul (2016) ise problem çözme sürecindeki temel basamaklarda ortaya çıkan bilgisayarca düşünme becerilerini Tablo 1'deki gibi ifade etmektedir.

Tablo 1. Problem Çözme Sürecinde Ortaya Çıkan Bilgisayarca Düşünme Becerileri (Kalelioğlu ve diğerleri, 2016)

\begin{tabular}{ll}
\hline Problem çözme süreci & Bilgisayarca düşünme becerileri \\
\hline 1) Problemi tanımlama & $\rightarrow$ Soyutlama, ayrıştırma \\
2) Veri toplama, sunma ve & $\rightarrow$ Veri toplama, veri analizi, örüntü tanıma, \\
görselleştirme & kavramsallaştırma, veri sunma \\
3) Çözümü planlama, seçme ve & $\rightarrow$ Matematiksel akıl yürütme, algoritma ve \\
genelleme & süreçleri inşa etme, eş zamanlı çalışma \\
4) Çözümü uygulama, & $\rightarrow$ Otomasyon, modelleme ve simülasyon \\
5) Çözümü değerlendirme ve & $\rightarrow$ Test etme, hata ayıklama, genelleme \\
iyileştirme için geliştirme &
\end{tabular}

Söz konusu araştırmacıların düşünceleri incelendiğinde bilgisayarca düşünmeye ilişkin bir görüş birliğine ulaşamadıkları söylenebilir. Bu karmaşık kuramsal yaklaşımlar bu kavramın alt boyutlar bazında daha detaylı incelenmesi gerektiğini göstermektedir. Tüm bu farklı bakış açılarından hareketle bilgisayarca düşünme, bireyin bir problemi çözerken zihinsel aktivitelerini yönlendirmesi, desteklemesi ve istenilen nitelikli çözüme ulaşması için eldeki mevcut bilgisayarı kapasitesi doğrultusunda etkili bir şekilde kullanması olarak ifade edilebilir. Bu süreçte birey bilgisayarca düşünme becerileri doğrultusunda bilgisayarı sürece entegre etmeye ve ondan maksimum verim almaya çalışmaktadır. $\mathrm{Bu}$ anlamda bilgisayar kullanmayı çok iyi bilmeyen kişiler bilgisayarın sürece entegre edilmediği bir çözüme odaklanabilirler. Fakat bilgisayar kullanmayı önemseyen ve bu anlamda kendisini geliştiren 
Y, Hıdıroğlu ve Ç. N, Hıdıroğlu/Pamukkale Üniversitesi Eğitim Fakültesi Dergisi, 52, 301-325, 2021305 kişilerin zihinsel şemaları matematiksel dünya ve bilgisayar dünyası arasında etkili ve sürekli bir etkileşim içerisine girmekte ve bu kişiler çok boyutlu düşünme yapıları ile daha detaylı düşünceleri içeren sonuçlara ulaşabilmektedir. Bilgisayarca düşünme becerisi yüksek düzeyde olan bir birey mevcut bilgisayarın yapabileceklerini, ilgili problem ile bilgisayar arasındaki ilişkiyi ve kendi yapabileceklerini dikkate alarak etkili bir entegrasyon gerçekleştirir.

Bilgisayarca düşünmenin önemli olduğu günümüzde çoklu zekâ kuramını geliştiren Gardner'ın ihtiyaç duyulan insan profilini açıklarken teknolojik, dijital veya bilgisayar temelli yeterliklere doğrudan vurgu yapmadığı söylenebilir. Örneğin Gardner (2006), geleceğe yön verecek ve geleceğin gerçek yaşam problemlerine hızlı ve etkili yanıtlar verebilecek zihinlerin öncelikle disiplinli, sentezci, yaratıcı, saygılı ve etik olmak üzere beş temel zihne sahip olması gerektiğini vurgulamaktadır.

\section{Eğitim ve Geleceği Şekillendirecek Beş Zihin}

Bilim ve teknolojinin artan gücü, farklı kültürlere sahip olan insanların sürekli dönüşüm ve etkileşim içinde olması eğitimi daha önemli hale getirmektedir. Gardner'ın beş zihin yaklaşımı, öğrencileri gerçek yaşamlarında güçlü kılmak ve onlara çevreyi kontrol edebilme ve yönlendirebilme becerilerini kazandırmak için önemli olmaktadır (Pava, 2008). Gardner'a göre (2006) bir zihinsel beceri, bireyin karşısına çıkan gerçek sorunları veya güçlükleri çözmesini, etkili bir ürün ortaya koymasını ve yeni bilgilere ulaşmak için ortam hazırlamasını içermelidir. Gardner'ın çoklu zekâ kuramında insanlarda bulunan, birbirinden bağımsız olarak bireylerde ortaya çıkabilen farklı bilişsel becerilerin her biri bir zekâ tipi olarak ele alınmaktadır. Gardner (2006), söz konusu zihin tiplerini birbirinden bağımsız bilişsel beceriler olarak ele almamaktadır. Ayrıca bu zihin tiplerinin, bireylerin düşünme yapısını ileri düzeyde destekleyeceğinden ve bu zihinlerin kendi aralarında birbirleri ile ilişkili olduğundan bahsetmektedir (bkz. Tablo 2). 
Tablo 2. Geleceği Şekillendirecek Beş Zihin (Gardner, 2006)

\begin{tabular}{|c|c|}
\hline Zihin Tipleri & İlgili Zihin Tipindeki Bireyin Özellikleri \\
\hline Disiplinli Zihin & $\begin{array}{l}\text { Disiplin/lere özgü düşünmede usta ve sürekli çalışarak kendini } \\
\text { geliştiren }\end{array}$ \\
\hline Sentezci Zihin & $\begin{array}{l}\text { Farklı önemli kaynaklardan alınan bilgiyi anlamlandıran, nesnel } \\
\text { değerlendiren ve anlamlı şekilde bütünleştiren }\end{array}$ \\
\hline Yaratıcı Zihin & $\begin{array}{l}\text { Yenilikçi; yeni fikirler tasarlayan, sorulmamış sorular soran, yeni } \\
\text { düşünme tarzları geliştiren, sıra dışı sonuçlara ulaşan }\end{array}$ \\
\hline Sayg1lı Zihin & $\begin{array}{l}\text { Bireysel ve grup olarak farklılıkları gören, farklı düşüncelere } \\
\text { hoşgörüyle yaklaşan ve farklı görüşleri önemseyen }\end{array}$ \\
\hline Etik Zihin & $\begin{array}{l}\text { Değerleri öne çıkaran, çalışan ve vatandaş olarak dünyadaki rolünün } \\
\text { kritik özelliklerini ortaya koyan ve buna uygun davranan, iyi çalışma } \\
\text { ve iyi vatandaşlık için çaba gösteren }\end{array}$ \\
\hline
\end{tabular}

Gardner (2006), öğrencilerin bu beş zihne ilişkin becerilerinin öğretmen tarafından performans gösterilerek, sorumluluk alınarak, proje üretilerek ve işbirlikli çalışma yapılarak geliştirilebileceğini belirtmektedir. Ancak Gardner (2006) öğretmenin de bu etkinlikleri derinleştirebilecek ve değerlendirebilecek ölçütlere sahip olmasının önemli ve gerekli bir unsur olduğunu vurgulamaktadır. Öğretmen uyguladığı etkinlik veya problemlerde; olası farklı yaklaşımların farkında olmalı, orijinal fikirlere çabuk adapte olarak onu özümseyebilmeli, öğrenme materyallerini öğrenci düzeyine uygun hale getirerek etkili bir şekilde kullanabilmeli, öğrenci görüşlerine saygılı olmalı, onların değerli olduğunu onlara hissettirmeli, öğrencilerin sürece etkin katılımlarını sağlamalı, etik unsurlara ve değerlere önem vererek etkili bir rol model olmalıdır. Benzer şekilde Gardner'ın (2006) beş zihninin gelişiminde öğretmen rolüne vurgu yapan Altındağ ve Senemoğlu (2018), yedinci sınıf matematik ve fen bilimleri derslerinde öğrencilerin sentezleyen zihin becerisinin göstergesi olan davranışları hangi düzeyde sergilediklerini inceledikleri çalışmada öğretme-öğrenme ortamında sentezleyen zihin özelliklerinin sergilenmesinin büyük ölçüde öğretmenin niteliğine bağlı olduğunu vurgulamaktadır. Davis ve Gardner (2012) ve Altındağ ve Senemoğlu'nun (2018) ifade ettiği gibi bu becerileri öğrencilere kazandırmada en önemli rol öğretmenlere düşmektedir. Bu nedenle, öğretme-öğrenme ortamında sentezleyen zihin gibi 
Gardner'ın beş zihne ait alt becerilerin geliştirilebilmesi için öncelikle disiplinler arası çok yönlü bakış açısına sahip, sentezleyen ve yaratıcı, saygıll, etik ve öğrencilere iyi bir rol model olacak öğretmenlere ihtiyaç vardır. Boix Mansilla ve Gardner (2011), öğrencilerin sürekli değişen dünyalarını anlamak için çok fazla bilgiden daha fazlasına ihtiyaç duyacaklarını ve bu başarabilmek için disipliner ve yaratıcı düşünmede ustalaşmaları gerektiklerini vurgulamaktadır. Bir diğer yandan Bowen'a (2013) 21. yüzyıl okul ortamında bireyler başkalarını yönlendirirken ve desteklerken sentezleyen zihin önemli olduğunu ifade etmektedir. Erik-Soussi (2008) ise sentezleyen zihnin; okul ortamındaki çoklu bakış açılarına bütüncül yaklaşmada yardımcı olduğunu, takım ruhunu desteklediğini, deneyim temelli bilgi düzeyini artırdığını belirtmektedir. Bilgisayarca düşünme gibi 21. yüzyıl dijital becerilerinin bu beş zihnin gelişimine önemli bir etkide bulunacaktır (Davis \& Gardner, 2012). Davis ve Gardner (2012) bunun bir nedeni olarak dijital dünyanın günümüz çocuklarının hayatlarının merkezinde yer almasını göstermekte ve dijital dünyanın ulaşılması hedeflenen beş zihne daha kolay ulaşmada etkili bir rol üstlenebileceğini ifade etmektedir. Burke ve Kafai (2010) öğrencilerin, oyunu zihinlerinde gerçek hayat şartlarına uygun olarak kurgulamalarının hayal gücünün gelişimini desteklediği ifade etmiştir. Burke ve Kafai (2010) bu şekilde bilgisayarca düşünme becerilerinden biri kabul edilen programlamanın Gardner'ın (2006) beşli zihin tipindeki yaratıcı zihni olumlu düzeyde etkilediğini dolaylı yoldan ifade etmektedir. Davis ve Gardner (2012) farklı bir açıdan da dijital dünyanın bir konu hakkında kısa sürede çok fazla doğru veya yanlış bilgiye ulaştırmasının sentez ve yaratıcılık için zorlaştırıcı bir unsur olabileceğine değinmektedir. Fakat bu zorlaştırıcı durumların ilgili becerilerin daha ileri düzeyde gelişmesine ortam sağlayacağı da düşünülebilir. Benzer şekilde matematik eğitimci Jo Boaler de hatalar, zorluklar ve mücadelenin beynin gelişimi için en iyi ortamları sağlayacağını ifade etmektedir. Farklı araştırmacıların bu düşünceleri bilgisayarca düşünme ve Gardner'ın beş zihni arasındaki ilişkinin karmaşık ve önemli bir araştırma konusu olabileceğini ortaya koymaktadır. Gardner (2006) da yaratıcılığın gerçekleşmesinde önemli unsurlardan birisinin bilgisayar programı hazırlayan yazılım mühendisi gibi bir bilim dalında uzmanlaşan ve sürekli olarak bu alanın farklı unsurlarını kullanan bir bireyler olduğunu ifade etmekte ve bilgisayarca düşünme ile yaratıcılık arasındaki ilişkiye vurgu yapmaktadır. 21 . yüzyıl yaratıcı zihinleri bilgisayar öncesi çağda hayal bile edilemeyecek şekilde entelektüel tasarımcılar olarak bilgisayarları kullanacaktır (Gardner, 2006). Bu da teknoloji ve zihin etkileşiminin önemini ortaya koyan bir başka ifadedir. 
Bunların yanında, matematik eğitiminde bilgisayarca düşünmenin öne çıktığı bazı durumlar olarak; (1) 21. yüzyıl becerileri arasında bilgisayarca düşünmenin öne çıkması, (2) 2023 eğitim vizyonundaki dijital dönüşümde olası başrolü, (3) matematiksel düşünme ile soyutlama, basitleştirme, algoritma oluşturma, örüntü tanıma, genelleme, mantıksal akı1 yürütme, hata ayıklama gibi önemli ortak bileşenlere sahip olması, (4) STEM' in (Science/ Technology/ Engineering/ Mathematics) teknoloji ayağında önemli rol oynaması, (5) matematik problemleri ile bütünleştirilmesinin problemlerin çözümünde yeni ve üst düzey stratejilere imkan vermesi, (6) teknolojik pedagojik alan bilgisi kuramsal çerçevesinde teknoloji temelli beceriyi temsil etmesi gösterilebilir. Matematik eğitiminde beşli zihin tiplerinin öne çıktığı bazı durumlar olarak ise; (1) matematik dersi öğretim programındaki yetkinliklerden biri olan inisiyatif alma ve girişimcilikte yaratıcı zihne yapılan vurgu, (2) yenilenmiş Bloom taksonomisinde 21. yüzyıl öğrenme sürecindeki üst düzey düşünme becerisi olan ortaya çıkarma basamağında sentez ve yaratıcı zihnin öne çıkması, (3) epistemoloji inanç düzeyi yüksek bireyler olarak ifade edilen görelilik sahibi bağlılık sahibi kişilerin sentezci ve saygılı zihne sahip olmaları, (4) öğrencilerin aktif katılımı gösterdiği demokratik sınıflarda farklı görüşlerin açığa çıkmasında öğretmenlerin saygılı zihne sahip olmalarının önemi, (5) teknolojik pedagojik alan bilgisi kuramsal çerçevesinde disiplinli zihnin alan bilgi ve becerisini temsil etmesi, (6) disiplinli zihnin STEM (Science/ Technology/ Engineering/ Mathematics)' in başta matematik olmak üzere bilim ve mühendislik boyutlarındaki önemi, (7) ilköğretim matematik öğretmenliği lisans öğretim programında eğitimde ahlak ve etik dersi ile etik zihnin önemine yapılan vurgu, (8) öğretmenlikte meslek etiği kavramından etik zihnin önemli olması, (9) öğretmenlik mesleği genel yeterliklerinde üç temel boyuttan biri olan tutum ve değerlerde etik ve saygılı zihne, diğer boyut olan mesleki becerilerde yaratıcı, sentezci ve disiplinle zihne yapılan vurgu gösterilebilir. Birçok araştırmacıya göre dijital dünyada teknoloji, dijitalleşme ve bilgisayar temelli becerilerden öne çıkanlardan biri olan bilgisayarca düşünme becerisi ile Gardner'in geleceği şekillendireceğini ifade ettiği beş zihin arasındaki ilişkinin; 21. yüzyıl öğrenme ortamlarında ihtiyaç duyulan öğrencilerin yetiştirileceği günümüzde oldukça önemli olduğu düşünülmektedir. Alanyazında bu iki temel değişkenin arasındaki ilişkiyi ele alan bir başka çalışma ile karşılaşılmaması da araştırmayı ön plana çıkaran bir diğer etken olmaktadır.

Bu doğrultuda çalışmanın amacı, matematik öğretmenlerinin; geleceği şekillendirecek zihin tipleri ile bilgisayarca düşünme becerileri arasındaki ilişkiyi açıklamaktır. Araştırmada ele alınan alt problemler aşağıda verilmiştir. 
Matematik öğretmenlerinin algılarına göre,

1) matematik öğretmenlerinin geleceği şekillendirecek zihin tipleri ve bilgisayarca düşünme becerileri ne düzeydedir?

2) matematik öğretmenlerinin geleceği şekillendirecek zihin tipleri ile bilgisayarca düşünme becerileri arasında anlamlı bir ilişki var mıdır?

3) matematik öğretmenlerinin geleceği şekillendirecek zihin tipleri, bilgisayarca düşünme becerilerinin anlamlı bir yordayıcısı mıdır?

\section{Yöntem}

\section{Araştırmanın Modeli}

Araştırma nicel-ilişkisel tarama modeli çalışmasıdır. İlişkisel tarama modeli ile bilgisayarca düşünme becerisi ve zihin tipleri değişkenleri arasındaki ilişkinin varlığının ve derecesinin ortaya koyulması amaçlanmaktadır. Araştırmada değişkenlerin birlikte değişip değişmedikleri, birlikte bir değişim varsa bunun ne düzeyde olduğu ve zihin tiplerinin bilgisayarca düşünmeyi yordayıp yordamadığı belirlenmeye çalışılmıştır.

\section{Evren ve Örneklem}

Araştırmanın evrenini Türkiye'de 2018-2019 eğitim öğretim yılında görev yapan matematik öğretmenleri oluşturmaktadır. Araştırmanın örneklem sayısının belirlenmesinde örneklem hesaplama formülü (Gay \& Airasian, 1996) dikkate alınmıştır ve bu doğrultuda en az 340 matematik öğretmenine ulaşılması hedeflenmiştir. Bu çalışma seçkisiz örnekleme yöntemine göre belirlenmiş ve gönüllü 481 matematik öğretmeni ile gerçekleştirilmiştir. Öğretmenlerin çeşitli değişkenlere göre dağılımı Tablo 3'te verilmiştir. 
310 Y, Hıdıroğlu ve Ç. N, Hıdıroğlu/Pamukkale Üniversitesi Eğitim Fakültesi Dergisi, 52, 301-325, 2021

Tablo 3. Çalışmadaki Matematik Öğretmenlerinin Demografik Özellikleri

\begin{tabular}{|c|c|c|c|}
\hline & Kişisel Bilgiler & $n$ & $\%$ \\
\hline \multirow{3}{*}{ Cinsiyet } & Kadın & 317 & $\% 66$ \\
\hline & & & \\
\hline & Erkek & 164 & $\% 34$ \\
\hline \multirow{5}{*}{ Yaş } & $20-30$ yaş & 157 & $\% 33$ \\
\hline & 31-40 yaş & 211 & $\% 44$ \\
\hline & & & \\
\hline & 41-50 yaş & 87 & $\% 18$ \\
\hline & 51 ve üzeri yaş & 26 & $\% 5$ \\
\hline \multirow{7}{*}{ Bölge } & Akdeniz & 81 & $\% 17$ \\
\hline & Doğu Anadolu & 41 & $\% 8.5$ \\
\hline & Ege & 69 & $\% 14$ \\
\hline & Güneydoğu Anadolu & 42 & $\% 9$ \\
\hline & $\dot{I}_{c ̧}$ Anadolu & 98 & $\% 20$ \\
\hline & Karadeniz & 46 & $\% 9.5$ \\
\hline & Marmara & 104 & $\% 22$ \\
\hline \multirow{3}{*}{ Kidem } & $0-10 y l l$ & 252 & $\% 52$ \\
\hline & $11-20 y l l$ & 166 & $\% 35$ \\
\hline & 21 ve üzeri yıl & 63 & $\% 13$ \\
\hline
\end{tabular}




Ortaokul $\quad 274 \quad \% 57$

Okul Türü

Lise $\quad 207 \quad \% 43$

\section{Veri Toplama Araçları}

Araştırmada veri toplama aracı olarak "Kişisel Bilgi Formu", "Bilgisayarca Düşünme Becerileri Ölçeği” ve "Zihin Tipleri Ölçeği” kullanılmıştır.

\section{Kişisel Bilgi Formu}

$\mathrm{Bu}$ kısımda, matematik öğretmenlerinin kendileriyle ilgili sorulara yer verilerek örneklem detaylı bir şekilde betimlenmiştir. Sorular cinsiyet (Kadın, Erkek); yaş (20-30 yaş; 31-40 yaş; $41-50$ yaş; 51 ve üzeri yaş); çalıştıkları bölge (Akdeniz; Doğu Anadolu; Ege; Güneydoğu Anadolu; İç Anadolu; Karadeniz; Marmara); kıdem (0-10 yll; 11-20 yll; 21 ve üzeri yıl); çalıştıkları okul türü (Ortaokul, Lise) değişkenleri ile ilgilidir.

\section{Bilgisayarca Düşünme Becerileri Ölçeği}

Araştırmada matematik öğretmenlerinin bilgisayarca düşünme becerilerini belirlemek amacıyla Korkmaz, Çakır ve Özden (2017) tarafından üniversite öğrencileri örneklemiyle geliştirilen “Bilgisayarca Düşünme Becerileri Ölçeği” kullanılmıştır. Ölçek 29 madde ve 5 boyuttan oluşmaktadır. Bu boyutlar; yaratıcılık (1., 2., 3., 4., 5., 6., 7., 8. maddeler), algoritmik düşünme (9., 10., 11., 12., 13., 14. maddeler), işbirliği (15., 16., 17., 18. maddeler), eleştirel düşünme (19., 20., 21., 22., 23. maddeler) ve problem çözmedir (24., 25., 26., 27., 28., 29. maddeler). Cronbach Alpha iç tutarlılık katsayıları "yaratıcılık" boyutunda .84; "algoritmik düşünme" boyutunda .87; "işbirliğii" boyutunda .87; "eleştirel düşünme" boyutunda .78 ve “problem çözme” boyutunda .73 olarak hesaplanmıştır. Ölçeğin toplam güvenirliği ise .82'dir. Faktörlerde elde edilen puanlara karş1lık gelen düzeyler şu şekilde verilmiştir: 20-51: Düşük Düzey; 52-67: Orta Düzey; 68-100: Yüksek Düzey. Faktörler varyansın \%56.1'ini açıklamaktadır.

\section{Zihin Tipleri Ölçeği}

Araştırmada matematik öğretmenlerinin zihin tiplerini belirlemek amacıyla Gardner'ın kuramsal çerçevesini dikkate alan ve Şan, Kış ve Erdemir (2018) tarafından üniversite 
öğrencileri örneklemiyle geliştirilen “Zihin Tipleri Ölçeği” kullanılmıştır. Ölçek 46 madde ve 5 boyuttan oluşmaktadır. Bu boyutlar; disiplinli zihin (1., 2., 3., 4., 5., 6., 7., 8., 9., 10. maddeler), sentezci zihin (11., 12., 13., 14., 15., 16., 17., 18., 19., 20., 21. maddeler), yaratıc1 zihin (22., 23., 24., 25., 26., 27. maddeler), sayg1lı zihin (28., 29., 30., 31., 32., 33., 34. maddeler) ve etik zihindir (35., 36., 37., 38., 39., 40., 41., 42., 43., 44., 45., 46. maddeler). Cronbach Alpha iç tutarlılık katsayıları "disiplinli zihin” boyutunda .81; "sentezci zihin" boyutunda .85; "yaratıc1 zihin" boyutunda .66; "sayg1lı zihin" boyutunda .79 ve "etik zihin" boyutunda .81 olarak hesaplanmıştır. Ölçeğin toplam güvenirliği ise .83'tür.

Veri toplama sürecinde öncelikle ölçeği hazırlayan araştırmacılardan ölçek kullanım izinleri alınmıştır ve ölçekler dijital ortama aktarılmıştır. Örnekleme ulaşabilmek için sosyal medyada matematik öğretmenlerinin olduğu gruplarda çalışmanın içeriği ile birlikte ölçeklerin dijital ortamda bulundukları link paylaşılmıştır. Dijital ortamda veri toplama araçlarının başında çalışmaya ve çalışmadaki kavramlara ilişkin genel bir bilgilendirme yapılmıştır.

\section{Veri Analizi}

Çalışmanın örneklem grubunun demografik özelliklerini belirlemek ve betimlemek için yüzde ve frekans hesaplaması yapılmıştır. Matematik öğretmenlerinin geleceği şekillendirecek zihin tipleri ve bilgisayarca düşünme becerilerine ilişkin düzeylerini belirlemek (1. alt problem) için betimsel istatistikten; matematik öğretmenlerinin geleceği şekillendirecek zihin tipleri ile bilgisayarca düşünme becerileri arasındaki ilişkiyi (2. alt problem) belirlemek için korelasyon analizinden; matematik öğretmenlerinin geleceği şekillendirecek zihin tiplerinin bilgisayarca düşünme becerilerinin anlamlı bir yordayıcısı olup olmadığını (3. alt problem) belirlemek için regresyon analizinden yararlanılmıştır. Düzeyler, aritmetik ortalamalar 4.21-5.00 ise "çok yüksek"; 3.41-4.20 ise "yüksek"; 2.61-3.40 ise "orta"; 1.81-2.60 ise "düşük"; 1.00-1.80 ise "çok düşük” olarak belirlenmiştir.

\section{Bulgular}

Çalışmada, "Zihin Tipleri Ölçeği” ve "Bilgisayarca Düşünme Becerileri Ölçeği”nden elde edilen veriler, alt problemlere yanıt verecek uygun nicel veri analizi teknikleriyle analiz edilmiştir. Alt problemler doğrultusunda elde edilen bulgular tablolarla birlikte aşağıda verilmiştir. 
Araştırmanın 1. alt problemine yanıt vermek amacıyla betimsel istatistik teknikleri kullanılmıştır. Matematik öğretmenlerinin zihin tiplerine ve bilgisayarca düşünme becerilerine ilişkin algıları 5'li likert tipindeki ölçeklerle ölçülmüştür.

Tablo 4. Matematik Öğretmenlerinin Zihin Tipleri ve Bilgisayarca Düşünme Becerileri Düzeyleri

\begin{tabular}{ccccc}
\hline Boyutlar & $n$ & $\bar{x}$ & Ss & Düzey \\
\hline Disiplinli Zihin & 481 & 4.09 & .537 & Yüksek \\
Sentezci Zihin & 481 & 4.08 & .580 & Yüksek \\
Yaratıcı Zihin & 481 & 3.94 & .634 & Yüksek \\
Saygılı Zihin & 481 & 4.28 & .580 & Çok Yüksek \\
Etik Zihin & 481 & 4.38 & .455 & Çok Yüksek \\
Bilgisayarca Düşünme Becerileri & 481 & 4.32 & .419 & Çok Yüksek \\
\hline
\end{tabular}

Tablo 4 incelendiğinde, matematik öğretmenlerinin disiplinli, sentezci, yaratıcı zihin tiplerine ilişkin yüksek; saygılı ve etik zihin tiplerine ve bilgisayarca düşünme becerilerine ilişkin çok yüksek düzeyde bir algıya sahip oldukları görülmektedir.

\section{Matematik Öğretmenlerinin Zihin Tipleri ile Bilgisayarca Düşünme Becerileri Arasındaki İlişki}

Araştırmanın 2. alt problemi doğrultusunda, öncelikle matematik öğretmenlerinin zihin tiplerinin ve bilgisayarca düşünme becerilerine ilişkin verilerin normal dağılım gösterip göstermediğini belirlemek amacıyla çarpıklık ve basıklık katsayılarına bakılmıştır (bkz. Tablo 5). Karagöz'e (2016) göre, verilerin normal dağılım göstermesi için çarpıklık ve basıklık değerlerinin -2 ile +2 arasında değer alması gerekmektedir. Tablo 5 incelendiğinde matematik öğretmenlerinin disiplinli zihin, sentezci zihin, yaratıcı zihin, saygılı zihin, etik zihin ve bilgisayarca düşünme becerilerine ilişkin verilerin normal dağılım gösterdiği belirlenmiştir. 
Normal dağıllım gösteren verilerin analizinde parametrik vardamsal istatistik teknikleri kullanılmıştır.

Tablo 5. Matematik Öğretmenlerinin Zihin Tipleriyle Bilgisayarca Düşünme Becerilerine İlişkin Normallik Analizi Sonuçları

\begin{tabular}{|c|c|c|c|c|c|}
\hline Değişkenler & $\bar{x}$ & Ss & Çarpıklık & Basıklık & Dă̆glım \\
\hline Disiplinli Zihin & 4.09 & .537 & -.578 & .145 & Normal \\
\hline Sentezci Zihin & 4.08 & .580 & -.549 & .441 & Normal \\
\hline Yaratıcı Zihin & 3.94 & .634 & -.514 & .309 & Normal \\
\hline Sayg1lı Zihin & 4.28 & .580 & -.643 & .020 & Normal \\
\hline Etik Zihin & 4.38 & .455 & -.557 & -.256 & Normal \\
\hline Bilgisayarca Düşünme Becerileri & 4.32 & .419 & -.559 & .100 & Normal \\
\hline
\end{tabular}

Değişkenlere ilişkin veriler normal dağılım gösterdiği için değişkenler arasındaki ilişkinin varlığını ve derecesini belirlerken Pearson korelasyon analizi kullanılmıştır. Bu doğrultuda Tablo 6'da araştırmanın 2. alt problemi olan matematik öğretmenlerinin algılarına göre sahip oldukları geleceği şekillendirecek zihin tipleri ile bilgisayarca düşünme becerileri arasındaki ilişki ortaya koyulmuştur. Korelasyon katsayısının mutlak değer olarak .70 - 1.00 arasında olması yüksek; .30 - .70 arasında olması orta; .00 - .30 arasında olması düşük düzeyde ilişki olduğu anlamına gelmektedir (Büyüköztürk, 2012). 


\begin{tabular}{|c|c|c|c|c|c|c|c|c|}
\hline & $\bar{x}$ & Ss & 1 & 2 & 3 & 4 & 5 & 6 \\
\hline 1. Disiplinli Zihin & 4.093 & .532 & 1 & .800 & .547 & .370 & .471 & .608 \\
\hline 2. Sentezci Zihin & 4.089 & .580 & & 1 & .604 & .406 & .452 & .614 \\
\hline 3. Yaratıcı Zihin & 3.936 & .634 & & & 1 & .495 & .544 & .559 \\
\hline 4. Saygilı Zihin & 4.282 & .455 & & & & 1 & .535 & .475 \\
\hline 5. Etik Zihin & 4.383 & .455 & & & & & 1 & .597 \\
\hline 6. Bilgisayarca Düşünme Becerileri & 4.325 & .419 & & & & & & 1 \\
\hline
\end{tabular}

Tablo 6 incelendiğinde, matematik öğretmenlerinin disiplinli ve sentezci zihinleri arasında pozitif yönde yüksek düzeyde anlamlı bir ilişki bulunmuştur $(r=.800 ; p<.05)$. Ayrıca matematik öğretmenlerinin disiplinli zihinleri ile yaratıcı $(r=.547 ; p<.05)$, saygılı $(r=.370$; $p<.05)$ ve sentezci $(r=.471 ; p<.05)$ zihinleri arasında pozitif yönde orta; sentezci zihinleri ile yaratıc1 $(r=.604 ; p<.05)$, saygilı $(r=.406 ; p<.05)$ ve etik $(r=.535 ; p<.05)$ zihinleri arasında pozitif yönde orta; yaratıcı zihinleri ile saygılı $(r=.495 ; p<.05)$ ve etik $(.544 ; p<.05)$ zihinleri arasında pozitif yönde orta; saygılı zihinleri ile etik $(r=.535 ; p<.05)$ zihinleri arasında pozitif yönde orta düzeyde anlamlı bir ilişki elde edilmiştir. Matematik öğretmenlerinin disiplinli $(r=.608 ; p<.05)$, sentezci $(r=.614 ; p<.05)$, yaratıc1 $(r=.559 ; p<.05)$, sayg1lı $(r=.475 ; p<.05)$ ve etik $(r=.597 ; p<.05)$ zihin tipleri ile bilgisayarca düşünme becerileri arasında pozitif yönde orta düzeyde anlamlı ilişkiler ortaya çıkmıştır.

\section{Matematik Öğretmenlerinin Zihin Tiplerinin Bilgisayarca Düşünme Becerilerini Yordama}

\section{Düzeyleri}

Araştırmanın 3. alt problemi olan matematik öğretmenlerinin algılarına göre; sahip oldukları zihin tiplerinin bilgisayarca düşünme becerilerinin anlamlı bir yordayıcısı olup olmadığına ilişkin regresyon analizi sonuçları Tablo 7'de verilmiştir.

Tablo 7. Matematik Öğretmenlerinin Zihin Tiplerinin Bilgisayarca Düşünme Becerilerini Yordama Düzeyleri 


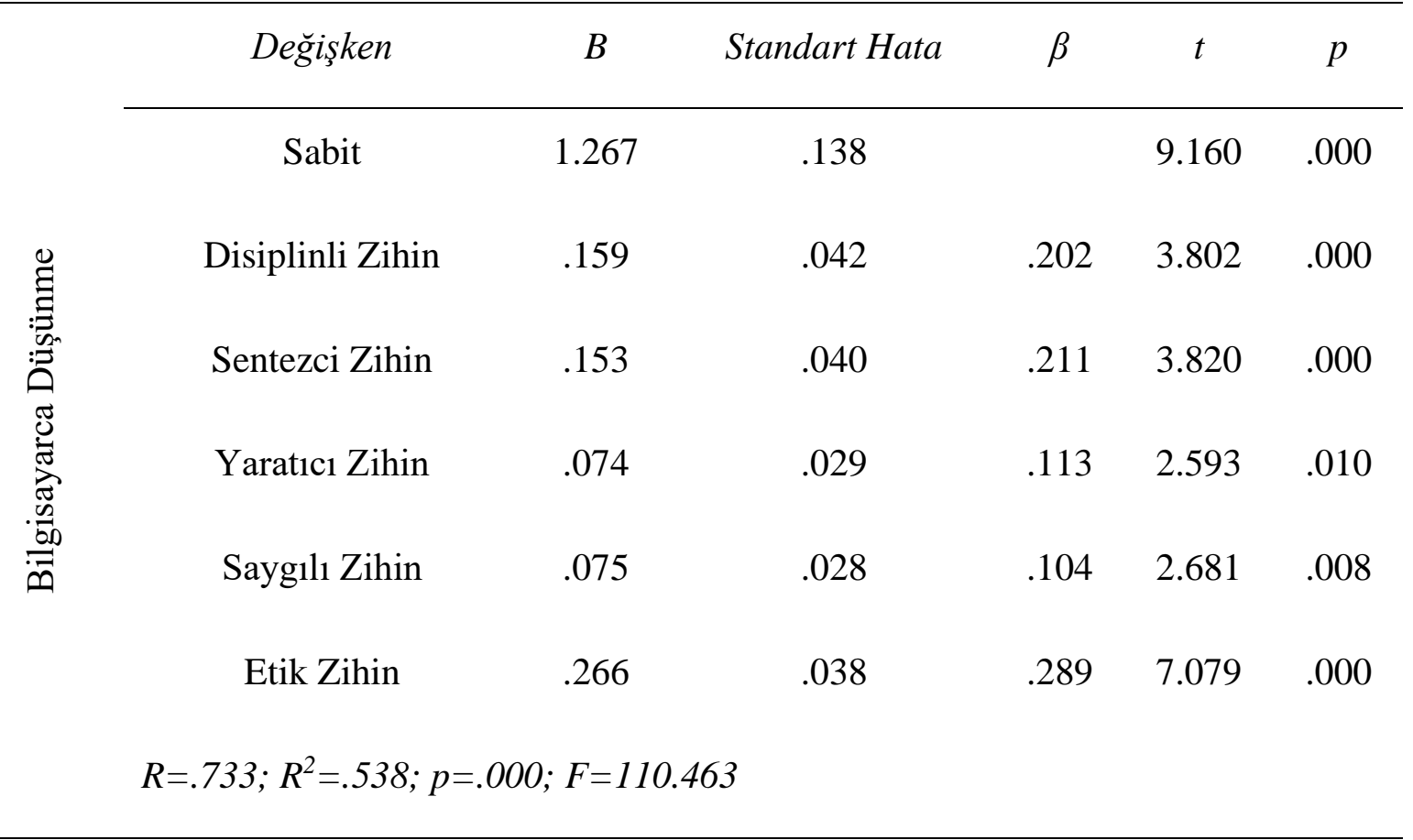

Tablo 7'deki $t$ değerleri ve standardize edilmiş $\beta$ katsayısı incelendiğinde, göreli önem düzeyine göre sırasıyla matematik öğretmenlerinin algılarına göre sahip oldukları etik, disiplinli, sentezci, saygılı ve yaratıcı zihnin onların bilgisayarca düşünme becerilerinin anlamlı bir yordayıcısı olduğu söylenebilir $\left(R=.733 ; R^{2}=.538\right)$. Matematik öğretmenlerinin algılarına göre sahip oldukları disiplinli, sentezci, yaratıcı, saygılı ve etik zihin onların bilgisayarca düşünme becerilerindeki toplam varyansın \%54'ünü açıklamaktadır. Standardize edilmiş regresyon katsayılarına göre matematik öğretmenlerinin algılarına göre sahip oldukları zihin tiplerinin onların bilgisayarca düşünme becerileri üzerindeki göreli önem sıraları etik zihin $(\beta=.266)$; disiplinli zihin $(\beta=.159)$; sentezci zihin $(\beta=.153)$; sayg1lı zihin $(\beta=.075)$ ve yaratıcı zihin $(\beta=.074)$ şeklinde olmuştur. Regresyon katsayılarının anlamlılığına ilişkin $\mathrm{t}$ testi sonuçlarına göre matematik öğretmenlerinin algılarına göre sahip oldukları disiplinli zihin $(t=3.802 ; p<.05)$, sentezci zihin $(t=3.820 ; p<.05)$, yaratıc1 zihin $(t=2.593$; $p<.05)$, saygılı zihin $(t=2.681 ; p<.05)$ ve etik zihin $(t=7.079 ; p<.05)$ onların bilgisayarca düşünme becerileri üzerinde anlamlı yordayıcılar olmaktadır.

\section{Sonuç, Tartışma ve Öneriler}

Çalışmanın bu bölümünde, matematik öğretmenlerinin algılarına göre, onların geleceğini şekillendirecek zihin tipleri ile bilgisayarca düşünme becerileri arasındaki ilişkinin açıklandığ 1 sonuçlara yer verilmiş, bu sonuçlar alan yazın ile karşılaştırılmış, ileriki çalışmalara ve uygulamaya dönük önerilere yer verilmiştir. 
Matematik öğretmenlerinin algılarına göre sahip oldukları saygılı, etik zihinleri ve bilgisayarca düşünme becerileri çok yüksek; disiplinli, sentezci ve yaratıcı zihinleri yüksek düzeydedir. Bu tür araştırmalarda öğretmenlerin algıları gerçekten sahip oldukları beceri düzeylerini yansıtmayabilir. Fakat sahip oldukları algılar özellikle kendilerini geliştirmeye ihtiyaç duyma, var olan eksikliklerini belirleme, uç durumları ortaya çıkarma vb. açılardan önemli olabilmektedir. Çalışmada ele alınan değişkenlere ilişkin öğretmen öz algılarının yüksek olması, onların kendilerini bu anlamda yeterli hissetmelerinden dolayı gelişmeleri için fazla çaba harcamayacakları durumunu ortaya çıkarabilir. Ayrıca değişkenlere ilişkin beceri düzeyleri ve öz algıları arasında anlamlı bir fark var ise bu durum onların öz farkındalıklarının düşük düzeyde olduğunu gösterebilir. $\mathrm{Bu}$ anlamda matematik öğretmenlerinin bu becerilere ilişkin sahip oldukları becerileri ortaya çıkaracak ve öz farkındalıklarını destekleyecek hizmet içi eğitimlere ve çalışmalara önemli olmaktadır. Yılmaz (2012), 6. sınıf fen ve teknoloji dersi öğrenci ders kitabında yer alan etkinliklerin \%99'unun disiplinli zihin, \%25'inin sentezci zihin, \%13'ünün yaratıcı zihin, \%11'inin saygılı zihin ve \%4'ünün etik zihin özelliklerini geliştirici nitelikte; öğrenci çalışma kitabında yer alan etkinliklerin \%98'inin disiplinli zihin, $\% 17$ 'sinin sentezci zihin, \%9'unun yaratıcı zihin, \%4'ünün saygılı zihin ve \%4'ünün etik zihin özelliklerini geliştirici nitelikte; öğretmen kılavuz kitabında yer alan etkinliklerin \%97'sinin disiplinli zihin, \%10'unun sentezci zihin, \%3'ünün yaratıcı zihin, \%7'sinin saygılı zihin özelliklerini geliştirici nitelikte olduğunu, etik zihin özelliklerini ise geliştirmediğini vurgulamaktadır. $\mathrm{Bu}$ araştırma sonucu, ders kitabı, çalışma kitabı ve öğretmen kılavuz kitaplarında yer alan etkinliklerin genellikle disiplinli ve sentezci zihin becerilerini kazandırmaya yönelik olduğunu ortaya koymaktadır. Disiplinli zihin özelliklerinin kazandırılmasında, bağlam temelli öğrenmeyi sağlama, disiplinlerdeki önemli konu ve kavramları belirleyerek o konu ve kavramlara önemli zaman ayırma, yapılan işe ilişkin geri bildirim verme, konuya değişik yönlerden yaklaşılmasını sağlama, öğrencilerin birden fazla disiplinde ustalaşmasını hedefleme ve disiplinli yaşamaya güdüleme gibi davranışların sergilenmesi gerekmektedir (Boix Mansilla \& Gardner, 2011; Gardner, 2006).

Matematik öğretmenlerinin algılarına göre sahip oldukları beşli (disiplinli, sentezci, yaratıcl, saygıll, etik) zihin ve bilgisayarca düşünme becerileri arasındaki ilişki incelendiğinde disiplinli ve sentezci zihin arasında pozitif yönde yüksek düzeyde; diğer değişkenler arasında ise pozitif yönde orta düzeyde anlamlı ilişkiler ortaya çıkmıştır. Gardner (2006), ortaya koyduğu beşli zihin tiplerinin kendi aralarında birbirlerini etkileyen bir yapıda olduğunu ve birbirlerini desteklediğini ifade etmektedir. Benzer şekilde, bu araştırmada da zihin tipleri 
arasında pozitif yönde orta veya yüksek düzeyde anlamlı ilişkiler ortaya çıkmıştır. Gardner (2006) çalışmasında disiplinli ve sentezci zihin arasındaki ilişkinin önemine ayrı bir vurgu yapmaktadır. Gardner'a (2006) göre, disiplinli bir zihin tek başına yeterli değildir. İleri düzey bir öğrenmede bilgi daha karmaşıklaşmakta ve disiplinler arası ilişki önem kazanmaktadır. Bu nedenle de insanlar gelecekte disipline özgü bilgileri sentezleştirme ve orijinal/alışılmadık yöntemlere yaymayı öğrenmelidir. Erik-Soussi (2008) sentezci zihnin; çok sayıda bakış açısıyla oluşturulan bütüncül bir kuramsal yapıyı anlamada, takım ruhunu geliştirmede, her geçen gün yaşantılarıyla sahip olunan bilgi düzeyini artırmada ve kurumsal bilgiyi diğerlerine aktarmada yardımcı olduğunu ifade etmektedir. Bowen (2013) sentezci zihnin; personeline yönlendirme desteği sağladığını, kurumla ilgili yönergeleri güncel halde bulundurmaya fırsat verdiğini, kurumun vizyonunu personele anlatmada ve çalışanları desteklemede kullanıldığını ifade etmektedir. Altındağ ve Senemoğlu (2018) yedinci sınıf öğrencilerinin sentezci zihin beceri düzeyleri ile matematik ve fen bilimleri dersi akademik başarı düzeyleri arasında pozitif yönde ve anlamlı düzeyde bir ilişki olduğunu ve farklı akademik başarı düzeyindeki öğrencilerin sentezci zihin beceri düzeyleri arasında, yüksek akademik başarı düzeyindeki öğrenciler lehine anlamlı fark olduğu ifade etmektedir. Sentezci düşünenlerin amacı, dışarıdan aldıkları bilgileri en kullanışı bir biçimde bir araya getirmektir. Bu da onların farklı derslere bilgiyi taşımalarına ve bilgiyi daha etkili bir şekilde kullanabilmelerine fırsat vermektedir. $\mathrm{Bu}$ durumun da akademik başarıyı arttırdığı söylenebilir. Bu nedenle öğretmen ve öğrenciler bilgiyi sentezleştirmeyi yani yeni ve farklı durumlara entegre etmeyi öğrenmelidir.

Gardner'ın (2006) saygılı ve etik zihni temelinde duyuşsal eylemleri içermektedir. Çalışmada matematik öğretmenlerinin algılarına göre sahip oldukları etik zihin-bilgisayarca düşünme ve saygılı zihin-bilgisayarca düşünme becerileri arasında pozitif yönde orta düzeyde anlamlı bir ilişki ortaya çıkmıştır. Yadav, Mayfield, Zhou, Hambrusch ve Korb (2014) bilgisayarca düşünmeyi problemlerin soyutlandığg ve otomatikleştirilmiş çözümlerin oluşturulduğu zihinsel bir süreç olarak ifade etmektedir. Bilgisayarca düşünme ile ilişkilendirilen bilişsel değişkenlerin yanında duyuşsal değişkenler de önemli bir çalışma alanıdır. Örneğin, Román-González, Pérez-González, Moreno-León ve Robles (2017) bilgisayarca düşünme kavramını kişilik özellikleri ile ilişkilendirmiştir. Román-González ve diğerleri (2017) beş değişken olan (vicdanlı olma, deneyime açık olma, dışa dönük olma, nazik olma ve duyuşsal dengesizlik) ve bilgisayarca düşünme becerileri arasındaki ilişkiyi incelemiştir. Román-González ve diğerleri (2017) bilgisayarca düşünme ile deneyime açık olma, dışa dönük olma ve vicdanlı olma değişkenleri arasında pozitif yönde anlamlı bir ilişki 
Y, Hıdıroğlu ve Ç. N, Hıdıroğlu/Pamukkale Üniversitesi Eğitim Fakültesi Dergisi, 52, 301-325, 2021319 olduğunu ifade etmektedir. Bu nedenle, bilgisayarca düşünmeyi güçlendirmeyi amaçlayan eğitim müdahalelerinde bilişsel becerilerin yanında duyuşsal ve psikomotor beceriler de dikkate alınmalıdır. Bir başka çalışmada, Yıldız Durak ve Sarıtepeci (2018) değişkenler tarafından sırasıyla düşünme stilleri, matematik dersi akademik başarısı, matematik dersine karşı tutumun; bilgisayarca düşünme becerisini yüksek düzeyde açıkladığını ifade etmektedir. Bu çalışmalara göre, düşünme yollarının bilgisayarca düşünme becerilerini öngören önemli etkenler olduğu tespit edilmiştir. Cohen'e (1998) göre, düşünme yollarının öğrenilmesi öğrencilerin yaratıcı öğrenme becerilerini geliştirecek, problem çözme ve soyutlama gibi becerilerinin gelişmesine firsat verecektir. Öğretmenlerin, bu amaçla öğrencilerin düşünme yollarını keşfetmelerini destekleyeceği düşünülmektedir. $\mathrm{Bu}$ çalışmada da, matematik öğretmenlerinin algılarına göre, sahip oldukları zihin tiplerinden sırasıyla etik, disiplinli, sentezci, saygılı ve yaratıcı zihin tiplerinin, bilgisayarca düşünme becerilerinin anlamlı birer yordayıcıları olduğu belirlenmiştir.

Matematik öğretmenlerinin bilgisayarca düşünme becerilerine ilişkin algılarının yüksek olması, onların bu becerilerinin yüksek olduğu anlamına gelmemektedir. Kimi zaman var olan durum ile olduğu sanılan durum arasında farklılıklar bulunabilir. 21. yy’da hem öğretmenlerin hem de öğrencilerin bu becerilerinin geliştirilmesi büyük önem taşımaktadır. Sentance ve Csizmadia (2017) öğretmenlerin programlamayı öğretmede kullandıkları stratejileri beşe ayırmaktadır. Bunlar; dijital olmayan etkinlikler, bağlam temelli etkinlikler, işbirlikli öğrenme, bilgisayarca düşünmeyi geliştirme, programlama görevlerini kademeli desteklemektir. Günümüzde bilgisayarca düşünme becerilerinin geliştirilmesinde dinamik yazılımlar, robotik araçlar ve elektronik legolar önemli birer araçtır. Bilgisayarca düşünmeyi arttırma çabalarının büyük bir çoğunluğunun ilköğretim düzeyinde olduğu ve bu yaştaki çocukların henüz somut işlemler dönemine geçemedikleri bilinmektedir. Özellikle bu noktada robotik gibi öğrenme yöntemleri öğrencilerin bilgisayarca düşünme kavramlarını somutlaştırmalarına, Kolb’un (1984) öne çıkardığı deneyimsel öğrenmelerine ve programlamaya motive olmalarına yardımcı olabilmektedir. Bu süreçte Scratch benzeri yazılımlar da bilgisayarca ve beşli zihin alanlarını geliştirici ortamlar yaratabilir. Ayrıca bilgisayarca düşünme sürecinin karmaşık yapısı, bu tür çalışmalarda genellemelere firsat sağlayan ölçeklerin dışında; süreç değerlendirmeyi de içeren nitel araştırmaları da önemli hale getirmektedir (Denner \& Werner, 2011). Nitel veya karma araştırmalarla matematik öğretmenlerinin ve öğrencilerinin bilgisayarca düşünme ve beşli zihin tiplerini öne çıkaracak farklı araştırmalar yürütülebilir. 
Araştırmada elde edilen sonuçlara göre, matematik öğretmenlerinin disiplinli, sentezci ve yaratıcı zihinlerine ilişkin algılarının saygılı ve etik zihinlerine ilişkin algılarından daha düşük olmasının nedenlerini ortaya koymaya yönelik nitel çalışmalar yapılabilir. Bu çalışma Türkiye'deki matematik öğretmenleri ile gerçekleştirilmiştir. Farklı kültürlerde ve branşlarda gerçekleştirilerek sonuçlar karşılaştırılabilir. Matematik öğretmenlerinin bilgisayarca düşünmeye ve zihin tiplerine ilişkin algılarındaki değişimin izlenmesi amacıyla boylamsal çalışmalar yapılabilir. Bilgisayarca düşünme becerilerinin ve zihin tiplerinin matematik öğretmenleri için önemli olan farklı değişkenlerle ilişkileri ve düzeyleri ortaya koyulabilir. Öğrenme süreçleri açısından matematik derslerinde Scratch, GeoGebra, Code.org ... vb. yazılımlar sayesinde bilgisayarca düşünmeleri ve farklı zihin tipleri geliştirilebilir ve kavramsal öğrenme desteklenebilir.

Etik Kurul İzin Bilgisi: Bu araştırma, Pamukkale Üniversitesi Sosyal ve Beşeri Bilimler Araştırma ve Yayın Etiği Kurulunun 28.08.2020 tarihli E.93803232-622.02-51022 sayılı kararı ile alınan izinle yürütülmüştür.

Çıkar Çatışması:Yazarların beyan edeceği bir çıkar çatışması yoktur.

Yazar Katkısı:Tüm yazarlar her aşamada çalışmaya katkı sağlamıştır. 


\section{Kaynakça}

Aldağ, H. ve Tekdal, M. (2015). Bilgisayar kullanımı ve programlama öğretiminde cinsiyet farklılıkları. Proceeding of 1.Uluslararası Çukurova Kadın Çalışmaları Kongresi (ss. 236-243) içinde. Adana, Türkiye.

Altındağ, M., \& Senemoğlu, N. (2018). Synthesizing mind skills scale: Synthesizing mind and academic achievement in 7th grade math \& science. Kastamonu Eğitim Dergisi, 26(5), 1701-1710.

Angeli, C., Voogt, J., Fluck, A., Webb, M., Cox, M., Malyn-Smith, J., \& Zagami, J. (2016). A K-6 computational thinking. Educational Technology ve Society, 19(3), 47-57.

Barr, D., Harrison, J., \& Conery, L. (2011). Computational thinking: A digital age skill for everyone. Learning \& Leading with Technology, 38(6), 20-23.

Barr, V., \& Stephenson, C. (2011). Bringing computational thinking to K-12: What is involved and what is the role of the computer science education community?. ACM Inroads, 2(1), 48-54.

Boix Mansilla, V., \& Gardner, H. (2011). Disciplining the mind, A. Ornstein, E. Pajak \& S. Ornstein (Eds), Contemporary issues in the curriculum (ss. 191-197) içinde. USA: Pearson.

Bowen, M. T. (2013). An examination of institutional advancement vice presidents' reports at four-year public and private historically black colleges and universities regarding their use of the five minds to promote stewardship. Yayımlanmamıs Doktora Tezi, Hartford Üniversitesi, Connecticut. UMI: 3561711.

Burke, Q., \& Kafai, Y. B. (2010). Programming \& storytelling: Opportunities for learning about coding \& composition. 19.01.2020 tarihinde http://hoc.elet.polimi.it/idc/2010/assets/doc/Burke_Kafai.pdf adresinden erişilmiştir.

Büyüköztürk, Ş. (2012). Sosyal bilimler için veri analizi el kitabı (16. Bask1). Ankara: Pegem Akademi.

Cohen, A. D. (1998). Strategies in learning and using a second language. London: Longman.

Çatlak, Ş., Tekdal, M. ve Baz, F. Ç. (2015). Scratch yazılımı ile programlama öğretiminin durumu: Bir doküman inceleme çalışması. Journal of Instructional Technologies \& Teacher Education, 4(3), 13-25. 
Çetin, İ. ve Toluk Uçar, Z. (2017). Bilgi işlemsel düşünme tanımı ve kapsamı. Y. Gülbahar. (Ed.), Bilgi işlemsel düşünmeden programlamaya (ss. 341-356) içinde. Ankara: Pegem Akademi.

Çınar, M. ve Tüzün, H. (2017). Eğitimde bilgisayımsal düşünme uygulamalarına ilişkin bir alanyazın incelemesi. 11. Uluslararası Bilgisayar ve Öğretim Teknolojileri Eğitimi Sempozyumu Özet Kitapçı̆̆ (ss. 311-312) içinde. Malatya, Türkiye.

Davis, K., \& Gardner, H. (2012). Five minds our children deserve: Why they're needed, how to nurture them. 12.01.2020 tarihinde http://cedar.wwu.edu/jec/vol6/iss1/10 adresinden erişilmiştir.

Denner, J., \& Werner, L. (2011). Measuring computational thinking in middle school using $\begin{array}{lll}\text { game } & \text { programming. } & 10.12 .2019\end{array}$ https://pdfs.semanticscholar.org/f629/baf5301d843c9f1d448edca901d0632dd278.pdf adresinden erişilmiştir.

Doğan, D., Çınar, M., Bilgiç, H. G. ve Tüzün, H. (2015). Sarmal eğitsel oyun tasarımı modeline göre dijital oyun geliştirme süreci: <E-adventure > örneği. Proceedings of International Play and Toy Congress (pp. 442-452) içinde. Erzurum, Türkiye.

Erik-Soussi, C. (2008). Leading in the liberal arts and postsecondary institutions: How five cognitive minds aid the good work of college presidents. Yayımlanmamıs Doktora Tezi, Hartford Üniversitesi, Connecticut. UMI: 3305570.

Gardner, H. (2006). Five minds for the future. USA: Harvard Business School Press.

Gay, L. R., \& Airasian, P. (1996). Educational research: Competencies for analysis and application (6th ed.). Upper Saddle River, NJ: Merrill/Prentice Hall.

Gotlieb, C.C., \& Borodin, A. (1973). Social issues in computing. Academic Press, New York, NY.

Kalelioğlu, F. ve Gülbahar, Y. (2015). Bilgi işlemsel düşünme nedir ve nasıl öğretilir?. 3th International Instructional Technology and Teacher Education Symposium Abstracts (ss. 42) içinde. Trabzon, Türkiye.

Kalelioğlu, F., Gülbahar, Y., \& Kukul, V. (2016). A framework for computational thinking based on a systematic research review. Baltic Journal of Modern Computing, 4(3), 583596. 
Y, Hıdıroğlu ve Ç. N, Hıdıroğlu/Pamukkale Üniversitesi Eğitim Fakültesi Dergisi, 52, 301-325, 2021323

Karagöz, Y. (2016). SPSS ve AMOS 23 uygulamal istatistiksel analizler. Ankara: Nobel Yayıncilik.

Kolb, D. (1984). Experiential learning: Experience as the source of learning and development. Englewood Cliffs, NJ: Prentice Hall.

Korkmaz, Ö., Çakır, R., \& Özden, M. (2016). Computational thinking levels scale (CTLS) adaptation for secondary school level. Gazi Journal of Education Sciences, 1(2), 143-162.

Korkmaz, Ö., Çakir, R., \& Özden, M. Y. (2017). A validity and reliability study of the computational thinking scales (CTS). Computers in Human Behavior, 72, 558-569.

Lee, I., Martin, F., Denner, J., Coulter, B., Allan, W., Erickson, J., \& Werner, L. (2011). Computational thinking for youth in practice. ACM Inroads, 2, 32-37.

Mannila, L., Dagiene, V., Demo, B., Grgurina, N., Mirolo, C., Rolandsson, L., \& Settle, A. (2014). Computational thinking in $K-9$ education. 21.01.2020 tarihinde http://www.di.unito.it/ barbara/MicRobot/Pubbl16/Wg\%20Iticse\%202016.pdf adresinden erişilmiştir.

Özçınar, H. (2017). Hesaplamalı düşünme araştırmalarının bibliyometrik analizi. Ĕgitim Teknolojisi Kuram ve Uygulama, 7(2), 149-171.

Özden, Y. (2003). Öğrenme ve ögretme (5. Bask1). Ankara: Pegem Akademi.

Özkeş, B. (2016). Bilişimsel düşünme temelli ders etkinliklerinin öğrencilerin eleştirel düşünme becerileri ve problem çözme becerilerine yönelik algllarl üzerine etkisinin incelenmesi. Yüksek Lisans Tezi. Mevlana Üniversitesi, Konya.

Pava, M. L. (2008). Loving the distance between them: Thinking beyond Howard Gardner's five minds fort he future. Journal of Business Ethics, 83, 285-296.

Riley, D. D., \& Hunt, K. A. (2014). Computational thinking for the modern problem solver. Boca Raton, FL: CRC Press.

Román-González, M., Pérez-González, J. C., \& Jiménez-Fernández, C. (2017). Which cognitive abilities underlie computational thinking? Criterion validity of the computational thinking test. Computers in Human Behavior, 72, 678-691.

Sayın, Z. ve Seferoğlu, S. S. (2016). Yeni bir 21. yüzyıl becerisi olarak kodlama eğitimi ve kodlamanın eğitim politikalarına etkisi. 05 Eylül 2020 tarihinde 

http://yunus.hacettepe.edu.tr/ \%20sadi/yayin/AB16_Sayin-Seferoglu_Kodlama.pdf adresinden erişilmiştir.

Sentance, S., \& Csizmadia, A. (2017). Computing in the curriculum: Challenges and strategies from a teacher's perspective. Education and Information Technologies, 22, 469-495.

Şan, İ., A., \& Erdemir, N. (2018). Scale for five minds fort he future: Development, validity and reliability. 27. Uluslararası Eğitim bilimleri Kongresi, Antalya, Türkiye.

Şahiner, A. ve Kert, S. (2016). Komputasyonel düşünme kavramı ile ilgili 2006-2015 y1lları arasındaki çalışmaların incelenmesi. Avrupa Bilim ve Teknoloji Dergisi, 5(9), 38-43.

The International Society for Technology [ISTE] (2015). Computational thinking leadership toolkit. 07.11.2019 tarihinde https://id.iste.org/docs/ct-documents/ct-leadershipttoolkit.pdf?sfvrsn=4 adresinden erişilmiştir.

Thomas, J. O., Odemwingie, O. C., Saunders, Q., \& Watlerd, M. (2015). While enacting computational algorithmic thinking in the context of game design. Journal of Computer Science and Information Technology, 3(1), 15-33.

Weintrop, D., Beheshti, E., Horn, M.S., Orton, K., Jona, K., Trouille, L., \& Wilensky, U. (2014). Defining computational thinking for science, technology, engineering, and math. 02.02.2020 tarihinde https://ccl.northwestern.edu/2014/CT-STEM_AERA_2014.pdf adresinden erişilmiştir.

Wing, J. M. (2006). Computational thinking. 21.12.2020 tarihinde https://www.cs.cmu.edu/ 15110-s13/Wing06-ct.pdf adresinden erişilmiştir.

Yadav, A., Mayfield, C., Zhou, N., Hambrusch, S., \& Korb, J. T. (2014). Computational thinking in elementary and secondary teacher education. ACM Transactions on Computing Education (TOCE), 14(1), 371-400.

Yecan, E., Özçınar, H. ve Tanyeri, T. (2017). Bilişim Teknolojileri öğretmenlerinin görsel programlama öğretimi deneyimleri. İlköğretim Online, 16(1), 377-393.

Yıldız Durak, H., \& Saritepeci, M. (2018). Analysis of the relation between computational thinking skills and various variables with the structural equation model. Computers \& Education, 116, 191-202. 
Y, Hıdıroğlu ve Ç. N, Hıdıroğlu/Pamukkale Üniversitesi Eğitim Fakültesi Dergisi, 52, 301-325, 2021325

Yılmaz, G. (2012). Çokgenler konusunun ilköğretim 7. sınıf öğrencilerine Vee diyagramları ve zihin haritaları kullanılarak ögretimi. Yayımlanmamış yüksek lisans tezi. Kastamonu Üniversitesi, Fen Bilimleri Enstitüsü, Kastamonu. 


\title{
The Relationship between Mathematics Teachers' Mind Types and Computational Thinking Skills \\ Yeliz ÖZKAN HIDIROĞLU*, Çağlar Naci HIDIROĞLU**
}

- Received: 29 February 2020• Accepted: 17.12.2020 • Online First: 30.12 .2020

\begin{abstract}
The aim of the study is to investigate the relationship between the mind types of mathematics teachers which will shape the future and their computational thinking skills. The study was designed according to quantitative-relational survey model. This study was carried out with 481 volunteer mathematics teachers determined according to the random sampling method. "Computational Thinking Skills Scale" and "Mind Types Scale" were used as data collection tools in the study. In the analysis of the data, descriptive statistics, correlation and regression analyses were benefited. According to the perceptions of the mathematics teachers, the level of their ethical mind and computational thinking skills are "very high" while their disciplined mind, synthesizing mind, creating mind, respectful mind and quinary mind levels are high. Also, according to the perceptions of mathematics teachers, there is a high level significant positive relationship between their quinary minds and computational thinking skills, and their quinary minds (both in sub-dimesnions and as a whole) are a significant predictor of their computational thinking.
\end{abstract}

Key Words: Computational thinking, the five minds for future, mathematics teacher.

\section{Cited:}

Özkan Hıdıroğlu, Y., \& Hıdıroğlu, Ç. N. (2021). The relationship between mathematics teachers' mind types and computational thinking skills. Pamukkale University Journal of Education, 52, 301325.doi: 10.9779/pauefd.696511

\footnotetext{
* Mathematics Teacher, Republic of Turkey Ministry of National Education, yelizozkan09@gmail.com, ORCID ID: https://orcid.org/0000-0002-5176-1235

** Corresponding Author, Assoc. Prof., Pamukkale University, Mathematics Education, Denizli, Turkey, chidiroglu@pau.edu.tr, ORCID ID: https://orcid.org/0000-0002-3774-4957
} 


\section{Introduction}

Scientific advancements not only increase the knowledge and skills of societies but also enable them to gain power in technology and thus in economy. Countries that aim to achieve a more powerful status takes into account the fact that in order to reach economic power, their technologies must develop and this can be achieved through scientific developments. Current economic development is directly associated with this interaction between science and technology. One of the most important goals of countries with this understanding is to raise skilled and pioneering individuals in science and technology with the quality education they will provide.

When the literature is examined, different learning approaches aiming at improving student and teacher competencies in the 21 st century are encountered. In order for countries to ensure the scientific and technological developments, the concept of computational thinking skill highlighted in education by Wing (2006) and Gardner (2006)'s five minds for the future are two noteworthy theoretical grounds.

\section{Computational Thinking in Education}

It can be observed in the literature that the concept of "computational thinking" has appeared in different terms in Turkish language such as bilgisayarca düşünme (computational thinking) (Çatlak, Tekdal, \& Baz, 2015; Korkmaz, Çakır, \& Özden, 2016; Özden, 2015); bilgisayımsal düşünme (computerised thinking) (Çınar \& Tüzün, 2017; Doğan, Çınar, Bilgiç, \& Tüzün, 2015); bilgi işlemsel düşünme (data processional process) (Çetin \& Toluk Uçar, 2017; Kalelioğlu \& Gülbahar, 2015); bilişimsel düşünme (computational thinking) (Özkeş, 2016; Sayın \& Seferoğlu, 2016); kompütasyonel düşünme (computational thinking) (Aldağ \& Tekdal, 2015; Şahiner \& Kert, 2016) and hesaplamalı düşünme (computational thinking) (Özçınar, 2017; Yecan, Özçınar, \& Tanyeri, 2017). As Piaget stated, the way a concept is perceived (mental scheme) is more important than naming the concept itself. Although the researchers were equally close to each of these terms, they decided to use the term "computational thinking" since they desired to ensure a language unity in the study and also because "Computational Thinking Skills Scale" prepared by Korkmaz et al. (2016) was used in the study.

Wing (2006), who highlighted the concept of computational thinking, first expressed by Seymour Papert in 1980, in today's education literature, noted that computational thinking is a necessary skill not only for computer experts but for everyone in the 21 st century. 
Y, Özkan Hıdıroğlu \& Ç. N, Hıdıroğlu/Pamukkale University Journal of Education, 52, 301-325, 2021303

According to Wing (2006), computational thinking includes critical thinking, algorithmic thinking, creativity and collaborative learning as well as the methods of using digital tools necessary for solving problems and their reflection on real life. The International Society for Technology [ISTE] (2015) underlined that computational thinking, a form of analytical thinking, should be included in the skills that all children should have, such as reading, writing and arithmetic operations. Gotlieb and Borodin (1973) stated that the methods in computer sciences are not only the means to develop computer softwares or hardwares but also useful in all application areas, and that the integration of computer science into all fields in the $21 \mathrm{st}$ century will become a basic skill to be learned starting from a young age such as reading, writing and arithmetic.

Different researchers have defined computational thinking in different ways. According to Mannila, Dagiene, Demo, Grgurina, Mirolo, Rolandsson, and Settle (2014), computational thinking is to use concepts and processes in computer science to formulate problems in different disciplines and produce solutions. Thomas, Odemwingie, Saunders, and Watlerd (2015) described computational thinking as the processes of defining and understanding a problem and introducing algorithms for solving the problem. Riley and Hunt (2014) elaborated the concept of computational thinking as thinking and questioning like computer scientists, with an emphasis on cognitive processes. Y1ldiz Durak and Sarıtepeci (2018) listed the features of computational thinking as follows: formulating the problem using computer, organizing and analyzing information logically, visualizing information with models or simulations, automating the problem with algorithmic thinking, revealing possible solutions for effective and more effective results, identifying the necessary resources and steps, generalizing the problem outcomes and transferring them to different situations.

Classifications related to computational thinking are as follows: For Lee, Martin, Denner, Coulter, Allan, Ericsson, and Werner (2011), computational thinking includes abstraction and automation. For Barr and Stephenson (2011), the components are abstraction, algorithm-procedures, automation, decomposition, parallel processing, and simulation. Angeli, Voogt, Fluck, Webb, Cox, Malyn-Smith, \& Zagami (2016) treat it as abstraction, algorithm, decomposing, debugging, and generalization. Weintrop, Beheshti, Horn, Orton, Jona, Trouille, and Wilensky (2014) discussed computational thinking under four subheadings. These include the followings: data and information skills (collecting data, creating data, manipulating data, analyzing data and visualizing data), modeling and simulation skills (using computational models to understand a concept, understanding how and why 
computational models work, evaluating computational models, using computational models to find solutions and test them, creating new models, and expanding existing models); computational problem solving skills (catching and debugging errors, programming, choosing effective computational tools, measuring different approaches / solutions for a problem, developing modular computational solutions, using problem solving strategies and creating abstractions) and systems management skills (examining a system as a whole, understanding relationships within a system, thinking at levels and visualizing systems, identifying, understanding and managing complexity). Kalelioğlu, Gülbahar, and Kukul (2016) explained the computational thinking skills that appear in the basic steps in the problem solving process as shown in Table 1.

Table 1. Computational Thinking Skills Appearing in the Problem Solving Process (Kalelioğlu et al., 2016)

\section{Problem solving process Computational Thinking Skills}

1) Defining the problem

2) Data collection, presentation and visualization

3) Planning the solution, Selection and generalization

4) Applying the solution

5) Evaluating the solution and improving $\rightarrow$ Abstraction, decomposition

$\rightarrow$ Data collection, data analysis, pattern recognition, conceptualization, data presentation

$\rightarrow$ Mathematical reasoning, building algorithms and processes, working simultaneously

$\rightarrow$ Automation, modeling and simulation

$\rightarrow$ Testing, debugging, generalizing

When the definitons of abovementioned researchers are examined, it can be observed that they could not reach a consensus about computational thinking. These complex theoretical approaches indicate that this concept should be examined in more detail on the basis of subdimensions. Considering all these different perspectives, computational thinking can be elaborated as an individual's effective use of an available computer in line with its capacity in order to direct and support his mental activities and to reach the desired quality solution while solving a problem. In this process, the individual tries to integrate the computer into the process in accordance with his computer thinking skills and get maximum efficiency from it. 
Y, Özkan Hıdıroğlu \& Ç. N, Hıdıroğlu/Pamukkale University Journal of Education, 52, 301-325, 2021305

In this sense, people who do not know how to use a computer very well can focus on a solution in which the computer is not integrated into the process. However, the mental schemas of people who care about using computers and develop themselves in this sense enter into an effective and continuous interaction between the mathematical world and the computer world, and these people can reach results that include more detailed thoughts with their multidimensional thinking structures. An individual with a high level of computational thinking skills performs an effective integration by considering what the available computer can do, the relationship between the related problem and the computer, and what he can do.

It can be said that Gardner, who developed the theory of multiple intelligences, did not directly emphasize technological, digital or computer-based competencies while mentioning the human profile needed in today's world where computational thinking is essential. For instance, Gardner (2006) stressed that the minds that can direct the future and provide fast and effective answers to the real-life problems of the future should embody five basic minds including the disciplined, synthesizing, creating, respectful and ethical minds.

\section{Five Minds That Will Shape Education and the Future}

The increasing power of science and technology and the constant transformation and interaction of people with different cultures make education more important. Gardner's five minds approach is of critical significance to empower students in their real lives and to gain them the skills to control and direct the environment (Pava, 2008). According to Gardner (2006), a mental skill should include solving the real problems or difficulties encountered by the individual, producing an effective product and preparing an environment to reach new information. In Gardner's theory of multiple intelligences, each of the different cognitive skills that can appear in individuals independently of each other is considered as an intelligence type. Gardner (2006) does not treat these mind types as seperate cognitive skills independent of each other. He also mentions that these minds will considerably support the thinking structure of individuals and that they are interrelated (see Table 2). 
Table 2. Five Minds for the Future (Gardner, 2006)

\section{Mind Types $\quad$ Characteristics of the Individual}

$\begin{array}{ll}\text { The Disciplined } & \text { Having mastery in disciplined thinking and developing oneself through } \\ \text { Mind } & \text { constant work }\end{array}$

The Synthesizing Making sense of the information obtained from different important Mind sources, evaluating it objectively and integrating it meaningfully

The Creating Mind Innovative; desiging new ideas, asking questions that haven't been asked, developing new thinking styles, reaching extraordinary results

The Respectful Realising individual and group differences, approaching different Mind thoughts with tolerance and appreciating different opinions

Highlighting values, fulfilling the critical characteristics of his role as a The Ethical Mind worker and citizen in the world and behaving accordingly, striving for good work and good citizenship

Gardner (2006) stressted that students' skills regarding these five minds can be developed by the teacher through practicing, taking responsibility, producing projects and collaborative work. Besides, Gardner (2006) emphasized that it is also vital and necessary for the teacher to have the criteria to make the activities more comprehensive and to evaluate them. The teacher should be aware of the possible different approaches in the activities or problems he / she applies, must be able to quickly adapt and implement original ideas, adapt the learning materials to the student level and use them effectively, respect the student views, make them feel that they are valuable, ensure the active participation of students in the process, be an effective role model by giving importance to ethical elements and values. Similarly, Altındağ and Senemoğlu (2018), who emphasized the role of teachers in the development of Gardner's (2006) five minds, in their study, where they examined the seventh graders' behaviors that are indicative of the synthesizing mind in mathematics and science lessons, underlined that the display of the synthesizing mind features in the teaching-learning environment depends largely on the quality of the teacher. As stated by Davis and Gardner (2012) and Altındağ and Senemoğlu (2018), teachers play the most important role to make students gain these skills. Therefore, in order to develop the sub-skills of Gardner's five minds, such as the synthesizing mind in the teaching-learning environment, there is a need for the 
Y, Özkan Hıdıroğlu \& Ç. N, Hıdıroğlu/Pamukkale University Journal of Education, 52, 301-325, 2021307 teachers who have a multidisciplined perspective, synthesize and are creative, respectful, ethical and good role models for students. Boix Mansilla and Gardner (2011) revealed that students will need more than a lot of information to understand their ever-changing world, and they need to master disciplined and creative thinking to achieve this. On the other hand, Bowen (2013) argued that the synthesizing mind is essential while individuals are guiding and supporting others in the 21st century school environment. According to Erik-Soussi (2008), the synthesizing mind ensures a holistic approach to multiple perspectives in the school environment, supports team spirit, and increases experience-based knowledge. 21 st century digital skills such as computational thinking will have a significant impact on the development of these five minds (Davis \& Gardner, 2012). For Davis and Gardner (2012), one reason underlying this situation is the fact that the digital world is at the center of the lives of today's children, and they suggested that the digital world can play an effective role in reaching the targeted five minds more easily. Burke and Kafai (2010) asserted that students' fictionalizing games in their minds in accordance with real life conditions supports the development of their imagination. Burke and Kafai (2010) indirectly stated that programming, which is accepted as one of the computational thinking skills, positively affects the creative mind type belonging to Gardner's (2006) five- mind types. From a different perspective, Davis and Gardner (2012) pointed out that, the fact that it is possible to reach too much true or false information about a subject in a short time through the digital world can create difficulty for synthesis and creativity. However, it can be considered that these challenging situations will provide an environment for the further development of the relevant skills. Likewise, math educator Jo Boaler maintained that mistakes, difficulties, and struggle will provide the best environments for brain development. These views from different researchers reveal that the relationship between computational thinking and Gardner's five minds can be a complex and important research topic. Gardner (2006) also alleged that one of the important elements in the realization of creativity for an individual is to specialize in a discipline such as software engineering that prepares a computer program and to constantly use different elements of this discipline, and he emphasized the relationship between computational thinking and creativity. 21 st century creative minds, as intellectual designers, will use computers in ways that are unimaginable in the pre-computer age (Gardner, 2006). This is another statement that reveals the importance of technology and mind interaction.

In addition to these, some of the situations where computational thinking stands out in mathematics education can be listed as follows: (1) The prominence of computational thinking 
among 21st century skills, (2) its possible leading role in the digital transformation of the 2023 education vision, (3) its having common components with mathematical thinking such as abstraction, simplification, algorithm creation, pattern recognition, generalization, logical reasoning, debugging, (4) its significant role in technology dimension of STEM (Science / Technology / Engineering / Mathematics), (5) its ensuring new and high-level strategies in solving problems when integrated with mathematical problems, (6) its representation of technology-based skills within the theoretical framework of technological pedagogical content knowledge.

Some cases in which the five-mind types come to the fore in mathematics education can be listed as follows: (1) the emphasis on taking initiative and the creative mind in entrepreneurship, which is one of the competencies in the mathematics curriculum, (2) prominence of the synthesing and creative mind in creation step of the revised Bloom's taxonomy, which is a high-level thinking skill in the 21st century learning process, (3) the fact that dedicated individuals having relativity, who are considered as individuals with a high level of epistemology beliefs, have the synthesizing and respectful minds, (4) the importance of teachers' having the respectful mind when different opinions are presented in democratic classes where students participate actively, (5) the disciplined mind's representing the field knowledge and skills in the theoretical framework of technological pedagogical content knowledge, (6) the importance of the disciplined mind in STEM (Science / Technology / Engineering / Mathematics), especially in mathematics, science and engineering dimensions, (7) The emphasis placed on the importance of ethical mind through ethics in education course in the undergraduate curriculum of primary mathematics education, (8) the importance of ethical mind in terms of professional ethics concept in teaching, (9) the emphasis on the ethical and respectful mind in attitudes and values, one of the three basic dimensions in the general competencies of the teaching profession, and the emphasis on the creative, synthesing and disciplined minds in professional skills, which is another dimension. According to many researchers, it is believed that the relationship between computational thinking skills, which is one of the leading technology, digitalization and computer-based skills in the digital world, and the five minds that will shape the future as stated by Gardner, is very important today in raising the students who are needed in 21 st century learning environments. Another factor that highlights the present study is that there is no other study encountered in the literature dealing with the relationship between these two basic variables. 
Y, Özkan Hıdıroğlu \& Ç. N, Hıdıroğlu/Pamukkale University Journal of Education, 52, 301-325, 2021309

With this regard, the aim of the study is to investigate the relationship between mathematics teachers' perceptual mind types that will shape the future and their computational thinking skills. The sub-problems addressed in the study are presented below:

According to the perceptions of mathematics teachers,

1) What are the levels of mathematics teachers' mind types that will shape the future and computational thinking skills?

2) Is there a significant relationship between mathematics teachers' mind types that will shape the future and their computational thinking skills?

3) Are mathematics teachers' mind types that will shape the future a meaningful predictor of their computational thinking skills?

\section{Method}

\section{Research Design}

The study was designed according to quantitative-relational survey model. It was aimed to reveal if there was a relationship between the variables of computational thinking skill and mind types with the relational scanning model. In the study, it was also intended to determine whether the variables changed together; if there was a mutual change, to what extent it was; and whether the types of mind predicted computational thinking.

\section{Population and Sample}

The population of the study consisted of the math teachers who worked in the 2018-2019 academic year in Turkey. The sample calculation formula (Gay \& Airasian, 1996) was taken into consideration in determining the sample size of the study, and in this direction, it was aimed to reach at least 340 mathematics teachers. This study was carried out with 481 volunteer mathematics teachers who were determined according to the random sampling method. The distribution of teachers according to various variables is presented in Table 3. 
310 Y, Özkan Hıdıroğlu \& Ç. N, Hıdıroğlu/Pamukkale University Journal of Education, 52, 301-325, 2021

Table 3. Demographic Characteristics of Mathematics Teachers in the Study.

\begin{tabular}{|c|c|c|c|}
\hline & Details & $n$ & $\%$ \\
\hline \multirow{2}{*}{ Gender } & Female & 317 & $\% 66$ \\
\hline & Male & 164 & $\% 34$ \\
\hline \multirow{4}{*}{ Age } & $20-30$ & 157 & $\% 33$ \\
\hline & $31-40$ & 211 & $\% 44$ \\
\hline & 4150 & 87 & $0 / 18$ \\
\hline & 51 and over & 26 & $\% 5$ \\
\hline \multirow{7}{*}{ Region } & Mediterranean & 81 & $\% 17$ \\
\hline & Eastern Anatolia & 41 & $\% 8.5$ \\
\hline & Aegean & 69 & $\% 14$ \\
\hline & Southeastern Anatolia & 42 & $\% 9$ \\
\hline & Central Anatolia & 98 & $\% 20$ \\
\hline & Black Sea & 46 & $\% 9.5$ \\
\hline & Marmara & 104 & $\% 22$ \\
\hline \multirow{3}{*}{ Seniority } & $0-10$ & 252 & $\% 52$ \\
\hline & $11-20$ & 166 & $\% 35$ \\
\hline & 21 and over & 63 & $\% 13$ \\
\hline \multirow{2}{*}{ Type of School } & Secondary School & 274 & $\% 57$ \\
\hline & High School & 207 & $\% 43$ \\
\hline
\end{tabular}




\section{Data Collection Tools}

In the study, "Personal Information Form", "Computational Thinking Skills Scale" and "Mind Types Scale" were used as data collection tools.

Personal Information Form: In this section, the sample was described in detail through the questions about the mathematics teachers themselves. The questions covered the following variables: Gender (Female, Male); age (20-30 years old; 31-40 years old; 41-50 years old; 51 and over); the region where they work (Mediterranean, Eastern Anatolia, Aegean, Southeastern Anatolia, Central Anatolia, Black Sea, Marmara); seniority (0-10 years; 11-20 years; 21 years and above); the type of school they work (Secondary School, High School).

Computational Thinking Skills Scale: The "Computational Thinking Skills Scale" developed by Korkmaz, Çakır, and Özden (2017) with a sample of university students was used in the study in order to determine the computational thinking skills of the mathematics teachers. The scale consists of 29 items and 5 dimensions. These dimensions include creativity (1st, 2 nd, 3rd, 4th, 5th, 6th, 7th and 8th items), algorithmic thinking (9th, 10th, 11th, 12th, 13th, and 14th items), collaboration (15th, 16th, 17th, and 18th items), critical thinking (19th, 20th, 21st, 22nd and 23rd items), and problem solving (24th, 25th, 26th, 27th, 28th and 29th items). Cronbach Alpha internal consistency coefficients are calculated as .84 in the "creativity" dimension"; .87 in "algorithmic thinking" dimension; .87 in the "collaboration" dimension; .78 in the "critical thinking" dimension and .73 in the "problem solving" dimension. The total reliability of the scale is .82 . The levels corresponding to the scores obtained in the factors are given as follows: 20-51: Low Level; 52-67: Intermediate; and 68-100: High Level. The factors explain $56.1 \%$ of the variance.

Mind Types Scale: In the study, "Mind Types Scale", developed by Şan, Kış and Erdemir (2018) with the sample of university students which takes into account Gardner's theoretical framework was used in order to determine the mind types of the mathematics teachers. The scale consists of 46 items and 5 dimensions. These dimensions are as follows: the disciplined mind (items 1, 2, 3, 4, 5, 6, 7, 8, 9, 10), the synthesizing mind (items 11, 12, 13, 14, 15, 16, $17,18,19,20,21$ ), the creative mind (items 22, 23, 24, 25, 26, 27), the respectful mind (items 28, 29, 30, 31, 32, 33, 34) and the ethical mind (items 35, 36, 37, 38, 39, 40, 41, 42, 43, 44, 45, 46). Cronbach Alpha internal consistency coefficients are .81 in the "disciplined mind" dimension; .85 in the "synthesing mind" dimension; .66 in the "creative mind" dimension; .79 in the "respectful mind" dimension and .81 in the "ethical mind" dimension. The total reliability of the scale is calculated as .83 . 
During the data collection process, necessary permissions to use the scales were obtained from the researchers who developed the scales, and the scales were transferred to the digital environment. In order to reach the sample, the link of the scales together with some information related to content of the study was shared in the digital environment through social media including the groups with mathematics teachers. The participants were informed about the general scope of the study and the concepts in the study at the beginning of the data collection tools in the digital environment.

\section{Data Analysis}

Percentage and frequency calculations were performed so as to determine and describe the demographic characteristics of the sample group of the study. In order to determine the mathematics teachers' levels of mind types that will shape the future and computational thinking skills (1st sub-problem), descriptive statistics were used. Next, correlation analysis was benefited to determine the relationship between the mathematics teachers' mind types that will shape the future and their computational thinking skills (2nd sub-problem). Finally, regression analysis was performed to determine whether the mathematics teachers' mind types that will shape the future are a significant predictor of their computational thinking skills $(3 r d$ sub-problem). Considering the arithmetic mean scores, the levels were determined to be "very high" between 4.21-5.00; "high" between 3.41-4.20; "medium" 2.61-3.40; "low" between 1.81-2.60; "very low" between 1.00-1.80.

\section{Findings}

In the study, the data obtained from the "Mind Types Scale" and "Computational Thinking Skills Scale" were analyzed using the appropriate quantitative data analysis techniques to answer the sub-problems. The findings obtained in line with the sub-problems are presented below with tables.

\section{Mathematics Teachers' Mind Types and Computational Thinking Skill Levels}

Descriptive statistical techniques were used to answer the first sub-problem of the study. The mathematics teachers' perceptions of mind types and computational thinking skills were measured with five-point Likert type scales. 
Y, Özkan Hıdıroğlu \& Ç. N, Hıdıroğlu/Pamukkale University Journal of Education, 52, 301-325, 2021313

Table 4. Mathematics Teachers' Mind Types and Computational Thinking Skill Levels.

\begin{tabular}{ccccc}
\hline Variables & $n$ & $\bar{x}$ & Ss & Level \\
\hline The Disciplined Mind & 481 & 4.09 & .537 & High \\
The Synthesizing Mind & 481 & 4.08 & .580 & High \\
The Creating Mind & 481 & 3.94 & .634 & High \\
The Respectful Mind & 481 & 4.28 & .580 & Very High \\
The Ethical Mind & 481 & 4.38 & .455 & Very High \\
Computational Thinking & 481 & 4.32 & .419 & Very High \\
\hline
\end{tabular}

As can be seen in Table 4, the mathematics teachers' disciplined, synthesizing, creative mind types are high, while they have a very high level of perception of respectful and ethical mind types and computer thinking skills.

The Relationship between Mathematics Teachers' Mind Types and Computational Thinking Skills

In line with the second sub-problem of the study, firstly, the skewness and kurtosis coefficients were examined in order to determine whether the data related to the mathematics teachers' mind types and computational thinking skills showed normal distribution (see Table 5). According to Karagöz (2016), the skewness and kurtosis values should be between -2 and +2 in order for the data to show a normal distribution. When Table 5 is examined, it is determined that the data regarding the disciplined mind, synthesizing mind, creative mind, respectful mind, ethical mind and computational thinking skills of the mathematics teachers showed normal distribution. Parametric statistics techniques were used in the analysis of the normally distributed data. 

Thinking Skills.

\begin{tabular}{cccccc}
\hline Variables & $\bar{x}$ & Ss & Skewness & Kurtosis & Distribution \\
\hline The Disciplined Mind & 4.09 & .537 & -.578 & .145 & Normal \\
The Synthesizing Mind & 4.08 & .580 & -.549 & .441 & Normal \\
The Creating Mind & 3.94 & .634 & -.514 & .309 & Normal \\
The Respectful Mind & 4.28 & .580 & -.643 & .020 & Normal \\
The Ethical Mind & 4.38 & .455 & -.557 & -.256 & Normal \\
Computational Thinking & 4.32 & .419 & -.559 & .100 & Normal \\
\hline
\end{tabular}

Since the data related to the variables showed normal distribution, Pearson correlation analysis was used to determine the existence and degree of the relationship between variables. Accordingly, the relationship between the mathematics teachers' mind types for the future and their computational thinking skills, which is included in the second sub-problem of the study, is presented in Table 6. The correlation coefficient between .70 and 1.00 as an absolute value means that there is a high level of correlation; while the correleation is moderate between .30 - .70 and low between .00 and .30 (Büyüköztürk, 2012). 
Y, Özkan Hıdıroğlu \& Ç. N, Hıdıroğlu/Pamukkale University Journal of Education, 52, 301-325, 2021315

Table 6. The Relationship between Mathematics Teachers' Mind Types of and Computational Thinking Skills.

\begin{tabular}{|c|c|c|c|c|c|c|c|c|}
\hline Variables & $\bar{x}$ & Ss & 1 & 2 & 3 & 4 & 5 & 6 \\
\hline 1. The Disciplined Mind & 4.093 & .532 & 1 & .800 & .547 & .370 & .471 & .608 \\
\hline 2. The Synthesizing Mind & 4.089 & .580 & & 1 & .604 & .406 & .452 & .614 \\
\hline 3. The Creating Mind & 3.936 & .634 & & & 1 & .495 & .544 & .559 \\
\hline 4. The Respectful Mind & 4.282 & .455 & & & & 1 & .535 & .475 \\
\hline 5. The Ethical Mind & 4.383 & .455 & & & & & 1 & .597 \\
\hline 6. Computational Thinking & 4.325 & .419 & & & & & & 1 \\
\hline
\end{tabular}

Table 6 indicates that a highly significant positive correlation was found between the disciplined and synthesising minds of the mathematics teachers $(r=.800 ; p<.05)$. In addition, there is a moderate, positive correlation between the maths teachers' disciplined minds and creative minds $(\mathrm{r}=.547 ; \mathrm{p}<.05)$, respectful minds $(\mathrm{r}=.370 ; \mathrm{p}<.05)$, and synthesizing minds $(\mathrm{r}=.471 ; \mathrm{p}<.05)$. There is also a moderate, positive relationshiop between their synthesizing minds and creative minds $(\mathrm{r}=.604 ; \mathrm{p}<.05)$, respectful minds $(r=.406 ; p<.05)$ and ethical minds $(r=.535 ; p<.05)$. A positive moderate relationship was found between their creative minds and respectful minds ( $r=.495 ; p<.05)$, and ethical minds $(r=.544 ; p<.05)$, and between their respectful and ethical minds $(\mathrm{r}=.535 ; \mathrm{p}<.05)$. A moderate positive relationship was found between the maths teachers' computational thinking skills and disciplined minds $(r=.608$; $p<.05)$, synthesizing minds $(r=.614 ; p<.05)$, creative minds $(r=.559 ; p<.05)$, respectful minds $(r=.475 ; p<.05)$ and ethical minds $(r=.597 ; p<.05)$.

\section{Prediction Levels of Mathematics Teachers' Mind Types of Computer Thinking Skills.}

Regression analysis results regarding whether the mathematics teachers' mind types are a significant predictor of computer thinking skills, which is the third sub-problem of the study, are presented in Table 7. 
Table 7. Prediction Levels of Mathematics Teachers' Mind Types of Computer Thinking Skills.

\begin{tabular}{|c|c|c|c|c|c|c|}
\hline \multirow{8}{*}{ 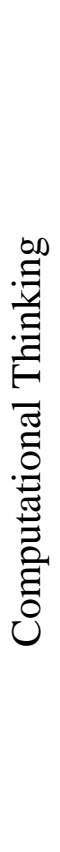 } & Variables & $B$ & Standard Error & $\beta$ & $t$ & $p$ \\
\hline & Constant & 1.267 & .138 & & 9.160 & .000 \\
\hline & The Disciplined Mind & .159 & .042 & .202 & 3.802 & .000 \\
\hline & The Synthesizing Mind & .153 & .040 & .211 & 3.820 & .000 \\
\hline & The Creating Mind & .074 & .029 & .113 & 2.593 & .010 \\
\hline & The Respectful Mind & .075 & .028 & .104 & 2.681 & .008 \\
\hline & The Ethical Mind & .266 & .038 & .289 & 7.079 & .000 \\
\hline & $=.733 ; R^{2}=.538 ; p=.00$ & $=110$. & & & & \\
\hline
\end{tabular}

When the $t$ values and the standardized $\beta$ coefficient in Table 7 are examined, it can be suggested that the maths teachers' ethical, disciplined, synthesizing, respectful and creative minds, respectively in the order of importance, are a significant predictor of their computational thinking skills $\left(R=.733 ; R^{2}=.538\right)$. The mathematic teachers' disciplined, synthesizing, creative, respectful and ethical minds they have according to their perceptions explain $54 \%$ of the total variance in their computational thinking skills. According to the standardized regression coefficients, the relative order of importance of the teachers' mind types on their computational thinking skills includes the ethical mind $(\beta=.266)$; disciplined mind $(\beta=.159)$; synthesizing mind $(\beta=.153)$; respectful mind $(\beta=.075)$ and creative mind ( $\beta=.074)$ respectively. According to the $\mathrm{t}$ test results regarding the significance of the regression coefficients, the mathematic teachers' perceptual disciplined minds $(t=3.802 ; \mathrm{p}$ $<.05)$, synthesising minds $(\mathrm{t}=3.820 ; \mathrm{p}<.05)$, creative minds $(\mathrm{t}=2.593 ; \mathrm{p}<.05)$, respectful minds $(\mathrm{t}=2.681 ; \mathrm{p}<.05)$ and ethical minds $(\mathrm{t}=7.079 ; \mathrm{p}<.05)$ are significant predictors of their computational thinking skills.

\section{Conclusion, Discussion, and Suggestions}

In this part of the study, the results regarding the relationship between the mathematics teachers' perceptual mind types for the future and their computational thinking skills are presented; these results are compared with the literature, and suggestions for future studies and applications are included. 
Y, Özkan Hıdıroğlu \& Ç. N, Hıdıroğlu/Pamukkale University Journal of Education, 52, 301-325, 2021317

According to the perceptions of the mathematics teachers, their level of respectful minds, ethical minds and computational thinking skills are very high while their disciplined, synthesizing and creative minds are at a high level. Teachers' perceptions may not reflect their actual skill levels in these kinds of studies. However, their perceptions are of critical importance in several aspects such as improving themselves, identifying existing shortcomings, revealing extreme situations and so on. The high self-perception of teachers regarding the variables discussed in the study may suggest that they will not make much effort for their development as they feel themselves competent in this sense. Besides, if there is a significant difference between the self-perceptions and skill levels regarding the variables, this may indicate that their self-awareness is low. In this sense, in-service trainings and studies that will reveal the skills that mathematics teachers have regarding these skills and enhance their self-awareness are essential. Y1lmaz (2012) stated that $99 \%$ of the activities in the 6th grade science and technology coursebook aimed at improving disciplined mind, 25\% of them were designed develop the synthesizing mind while $13 \%$ of them were reserved for the creative mind, $11 \%$ for the respectful mind and $4 \%$ for the ethical mind. He also added that $98 \%$ of the activities in the student workbook were designed for developing the disciplined mind, $17 \%$ for the synthesizing mind, $9 \%$ for the creative mind, $4 \%$ for the respectful mind and $4 \%$ for the ethical mind. Besides, $97 \%$ of the activities in the teacher's manual were devoted to developing the disciplined mind, $10 \%$ of them to the synthesizing mind, $3 \%$ of them to the creative mind, and $7 \%$ of them to the respectful mind features; however, they didn't cover the ethical mind features. The findings of this study reveals that the activities in the textbooks, workbooks and teacher's manuals are generally aimed at students'gaining the disciplined and synthesising mind skills. In order to ensure students' acquiring the disciplined mind qualities, the following behaviors should be demonstrated: providing context-based learning, identifying important subjects and concepts in the disciplines and allocating sufficient time to those subjects and concepts, giving feedback on the task performed, enabling students to approach the topics from different aspects, aiming for students to master more than one discipline and encouraging them to live in a disciplined way (Boix Mansilla \& Gardner, 2011; Gardner, 2006).

When the relationship between the five mind types ( the disciplined, synthesizing, creative, respectful, ethical) and computational thinking skills, which mathematics teachers have according to their perceptions, is examined, it was determined that there is a positive high level relationship between the disciplined and synthesising minds while there is a 
moderate, significant positive relationship between the other variables. Gardner (2006) proposed that the five mind types have a quality that affects and support each other. Similarly, it was revealed in this study that there were significant, positive, moderate or high relationships. Gardner (2006) specifically emphasized the importance of the relationship between the disciplined and synthesising mind in his study. According to Gardner (2006), a disciplined mind alone is not enough. In advanced learning, knowledge becomes more complex and interdisciplined relationship becomes more important. Therefore, in the future, people should learn to synthesize the disciplined knowledge and spread it to original / unconventional methods. Erik-Soussi (2008) asserted that the synthesising mind helps to understand a holistic theoretical structure formed with many perspectives, to develop team spirit, to increase the level of experiental knowledge acquired each day and to convey the institutional knowledge to others. According to Bowen (2013), the synthesizing mind provides support in guiding the staff of an organization, gives the opportunity to keep the institutional directions up to date, and is used to explain the vision of the institution to the personnel and support the employees. Altındağ and Senemoğlu (2018) found that there is a positive and significant relationship between seventh-grade students' synthesizing mind skill levels and their academic achievement levels in mathematics and science courses, and reported that there is a significant difference in the synthesizing mind skill levels of the students, who have different academic achievement levels, in favor of those with high academic achievement levels. The aim of the synthesising thinkers is to bring together the information they have received from outside in the most efficient way. This gives them the opportunity to use the information in different lessons and to use it more effectively. It can be suggested that this situation increases academic success. Therefore, teachers and students should learn to synthesize knowledge, that is, integrate it into new and different situations.

The respectful and ethical minds of Gardner (2006) basically include affective actions. In the study, a moderate positive correlation was found between the mathematics teachers's perceptual ethical mind and computational thinking, and between their respectful mind and computational thinking. Yadav, Mayfield, Zhou, Hambrusch, and Korb (2014) defined computational thinking as a mental process in which problems are abstracted and automated solutions are created. Besides the cognitive variables associated with computational thinking, affective variables are also an important field of study. For instance, Román-González, PérezGonzález, Moreno-León, and Robles (2017) associated the concept of computational thinking with personality traits. Román-González et al. (2017) examined the relationship between five 
variables (conscientiousness, openness to experience, extroversion, kindness, and affective instability) and computational thinking skills. Román-González et al. (2017) revealed that there is a positive significant relationship between computational thinking and the variables of opennes to experience, extrovertion, and conscientiousness. For this reason, affective and psychomotor skills as well as the cognitive skills should also be taken into consideration in educational interventions aimed at enhancing computational thinking. In another study, Y1ldız Durak and Saritepeci (2018) stated that thinking styles, academic achievement in mathematics lesson, and attitude towards mathematics lesson respectively explain computational thinking skill at a high level. According to these studies, it has been determined that thinking ways are important factors that predict computational thinking skills. According to Cohen (1998), learning the ways of thinking will improve students' creative learning skills, and will allow them to develop skills such as problem solving and abstraction. For this purpose, it is believed that teachers will support students to discover the ways of thinking. In this study, according to the perceptions of mathematics teachers, it was determined that ethical, disciplined, synthesizing, respectful and creative mind types are respectively significant predictors of computational thinking skills.

The mathematics teachers' high perception of computational thinking skills does not necessarily mean that these skills are high. Sometimes there may be differences between the current situation and the assumed situation. It is of great importance to develop these skills of both teachers and students in the 21st century. Sentance and Csizmadia (2017) divided the strategies that teachers use in teaching programming into five. These include non-digital activities, context-based activities, collaborative learning, developing computational thinking, supporting programming tasks gradually. Today, dynamic software, robotic tools and electronic legos are important tools in the developing computational thinking skills. It is evident that most of the efforts to increase computational thinking are at the primary education level and children at this age are not yet in the concrete operations period. Especially at this point, learning methods such as robotics can help students to embody the concepts of computational thinking, and support them in terms of experiential learning highlighted by Kolb (1984) and programming motivation. In this process, softwares such as Scratch can also create environments that develop computational thinking and five minds. In addition, the complex nature of the computational thinking process makes qualitative studies that include process evaluation important as well as the scales that allow generalizations in such studies (Denner \& Werner, 2011). Through qualitative or mixed research design methods, different 
studies can be conducted to reveal computational thinking skills and five mind types of mathematics teachers and students.

According to the results of the study, qualitative studies can be carried out to reveal the reasons why the perceptions of mathematics teachers about their disciplined, synthesizing and creative minds are lower than their respectful and ethical perceptions. This study was conducted with teachers of mathematics in Turkey. The results can be compared to the other studies performed in different cultures and branches. Longitudinal studies can be conducted in order to monitor the change in mathematics teachers' perceptions of computational thinking and mind types. Relationships of computational thinking skills and mind types with different variables that are important for mathematics teachers and the level of these relationships can be investigated. Thanks to the softwares such as Scratch, GeoGebra, Code.org... etc. benefited in mathematics lessons in terms of learning processes, computational thinking and different mind types can be enhanced and conceptual learning can be supported.

Ethical Approval: This research was conducted with the permission of the Pamukkale University ethics committee with the decision no E.93803232-622.02-51022 dated 28.08.2020.

Conflict of Interest: Authors have no conflict of interest to declare.

Author Contributions: All authors contributed to the study at every stage. 


\section{References}

Aldağ, H., \& Tekdal, M. (2015). Bilgisayar kullanımı ve programlama öğretiminde cinsiyet farklılıkları. In Proceeding of 1.Uluslararası Çukurova Kadın Çalışmaları Kongresi (pp. 236-243). Adana, Türkiye.

Altındağ, M., \& Senemoğlu, N. (2018). Synthesizing mind skills scale: Synthesizing mind and academic achievement in 7th grade math \& science. Kastamonu Education Journal, 26(5), 1701-1710.

Angeli, C., Voogt, J., Fluck, A., Webb, M., Cox, M., Malyn-Smith, J., \& Zagami, J. (2016). A K-6 computational thinking. Educational Technology ve Society, 19(3), 47-57.

Barr, D., Harrison, J., \& Conery, L. (2011). Computational thinking: A digital age skill for everyone. Learning \& Leading with Technology, 38(6), 20-23.

Barr, V., \& Stephenson, C. (2011). Bringing computational thinking to K-12: What is involved and what is the role of the computer science education community?. ACM Inroads, 2(1), 48-54.

Boix Mansilla, V., \& Gardner, H. (2011). Disciplining the mind. In A. Ornstein, E. Pajak \& S. Ornstein (Eds), Contemporary issues in the curriculum (pp. 191-197). USA: Pearson.

Bowen, M. T. (2013). An examination of institutional advancement vice presidents' reports at four-year public and private historically black colleges and universities regarding their use of the five minds to promote stewardship. Unpublished Doctoral Dissertation, University of Hartford, Connecticut. UMI: 3561711.

Burke, Q., \& Kafai, Y. B. (2010). Programming \& storytelling: Opportunities for learning about coding \& composition. Retrieved from http://hoc.elet.polimi.it/idc/2010/assets/doc/Burke_Kafai.pdf.

Büyüköztürk, Ş. (2012). Sosyal bilimler için veri analizi el kitabı (16. edition). Ankara: Pegem Akademi.

Cohen, A. D. (1998). Strategies in learning and using a second language. London: Longman.

Çatlak, Ş., Tekdal, M., \& Baz, F. Ç. (2015). Scratch yazılımı ile programlama öğretiminin durumu: Bir doküman inceleme çalışması. Journal of Instructional Technologies \& Teacher Education, 4(3), 13-25. 
Çetin, İ., \& Toluk Uçar, Z. (2017). Bilgi işlemsel düşünme tanımı ve kapsamı. In Y. Gülbahar. (Ed.), Bilgi işlemsel düşünmeden programlamaya (pp. 341-356). Ankara: Pegem Akademi.

Çınar, M., \& Tüzün, H. (2017). Eğitimde bilgisayımsal düşünme uygulamalarına ilişkin bir alanyazın incelemesi. In 11. Uluslararası Bilgisayar ve Öğretim Teknolojileri Eğitimi Sempozyumu Özet Kitapçı̆̆l (pp. 311-312). Malatya, Türkiye.

Davis, K., \& Gardner, H. (2012). Five minds our children deserve: Why they're needed, how to nurture them. Retrieved from http://cedar.wwu.edu/jec/vol6/iss1/10.

Denner, J., \& Werner, L. (2011). Measuring computational thinking in middle school using game programming. Retrieved from https://pdfs.semanticscholar.org/f629/baf5301d843c9f1d448edca901d0632dd278.pdf.

Doğan, D., Çınar, M., Bilgiç, H. G., \& Tüzün, H. (2015). Sarmal eğitsel oyun tasarımı modeline göre dijital oyun geliştirme süreci: <E-adventure $>$ örneği. In Proceedings of International Play and Toy Congress (pp. 442-452). Erzurum, Türkiye.

Erik-Soussi, C. (2008). Leading in the liberal arts and postsecondary institutions: How five cognitive minds aid the good work of college presidents. Unpublished Doctoral Dissertation, University of Hartford, Connecticut. UMI: 3305570.

Gardner, H. (2006). Five minds for the future. USA: Harvard Business School Press.

Gay, L. R., \& Airasian, P. (1996). Educational research: Competencies for analysis and application (6th edition). Upper Saddle River, NJ: Merrill/Prentice Hall.

Gotlieb, C.C., \& Borodin, A. (1973). Social issues in computing. Academic Press, New York, NY.

Kalelioğlu, F., \& Gülbahar, Y. (2015). Bilgi işlemsel düşünme nedir ve nasıl öğretilir?. In 3th International Instructional Technology and Teacher Education Symposium Abstracts (pp. 42). Trabzon, Türkiye.

Kalelioğlu, F., Gülbahar, Y., \& Kukul, V. (2016). A framework for computational thinking based on a systematic research review. Baltic Journal of Modern Computing, 4(3), 583596.

Karagöz, Y. (2016). SPSS ve AMOS 23 uygulamal istatistiksel analizler. Ankara: Nobel Yayıncilik. 
Y, Özkan Hıdıroğlu \& Ç. N, Hıdıroğlu/Pamukkale University Journal of Education, 52, 301-325, 2021323

Kolb, D. (1984). Experiential learning: Experience as the source of learning and development. Englewood Cliffs, NJ: Prentice Hall.

Korkmaz, Ö., Çakır, R., \& Özden, M. (2016). Computational thinking levels scale (CTLS) adaptation for secondary school level. Gazi Journal of Education Sciences, 1(2), 143-162.

Korkmaz, Ö., Çakir, R., \& Özden, M. Y. (2017). A validity and reliability study of the computational thinking scales (CTS). Computers in Human Behavior, 72, 558-569.

Lee, I., Martin, F., Denner, J., Coulter, B., Allan, W., Erickson, J., \& Werner, L. (2011). Computational thinking for youth in practice. ACM Inroads, 2, 32-37.

Mannila, L., Dagiene, V., Demo, B., Grgurina, N., Mirolo, C., Rolandsson, L., \& Settle, A. (2014). Computational thinking in $K-9$ education. Retrieved from http://www.di.unito.it/ barbara/MicRobot/Pubbl16/Wg\%20Iticse\%202016.pdf.

Özçınar, H. (2017). Hesaplamalı düşünme araştırmalarının bibliyometrik analizi. Ĕgitim Teknolojisi Kuram ve Uygulama, 7(2), 149-171.

Özden, Y. (2003). Ögrenme ve ögrretme (5th edition). Ankara: Pegem Akademi.

Özkeş, B. (2016). Bilişimsel düşünme temelli ders etkinliklerinin öğrencilerin eleştirel düşünme becerileri ve problem çözme becerilerine yönelik algllarl üzerine etkisinin incelenmesi. Unpublished Master Dissertation, Mevlana University, Konya.

Pava, M. L. (2008). Loving the distance between them: Thinking beyond Howard Gardner's five minds fort he future. Journal of Business Ethics, 83, 285-296.

Riley, D. D., \& Hunt, K. A. (2014). Computational thinking for the modern problem solver. Boca Raton, FL: CRC Press.

Román-González, M., Pérez-González, J. C., \& Jiménez-Fernández, C. (2017). Which cognitive abilities underlie computational thinking? Criterion validity of the computational thinking test. Computers in Human Behavior, 72, 678-691.

Sayın, Z., \& Seferoğlu, S. S. (2016). Yeni bir 21. yüzyıl becerisi olarak kodlama eğitimi ve kodlamanın eğitim politikalarına etkisi. Retrieved from http://yunus.hacettepe.edu.tr/ \%20sadi/yayin/AB16_Sayin-Seferoglu_Kodlama.pdf.

Sentance, S., \& Csizmadia, A. (2017). Computing in the curriculum: Challenges and strategies from a teacher's perspective. Education and Information Technologies, 22, 469-495. 
Şan, İ., A., \& Erdemir, N. (2018). Scale for five minds fort he future: Development, validity and reliability. 27. Uluslararası Eğitim bilimleri Kongresi, Antalya, Türkiye.

Şahiner, A., \& Kert, S. (2016). Komputasyonel düşünme kavramı ile ilgili 2006-2015 y1lları arasındaki çalışmaların incelenmesi. Avrupa Bilim ve Teknoloji Dergisi, 5(9), 38-43.

The International Society for Technology [ISTE] (2015). Computational thinking leadership toolkit. Retrieved from https://id.iste.org/docs/ct-documents/ct-leadershipttoolkit.pdf?sfvrsn=4.

Thomas, J. O., Odemwingie, O. C., Saunders, Q., \& Watlerd, M. (2015). While enacting computational algorithmic thinking in the context of game design. Journal of Computer Science and Information Technology, 3(1), 15-33.

Weintrop, D., Beheshti, E., Horn, M.S., Orton, K., Jona, K., Trouille, L., \& Wilensky, U. (2014). Defining computational thinking for science, technology, engineering, and math. Retrieved from https://ccl.northwestern.edu/2014/CT-STEM_AERA_2014.pdf.

Wing, J. M. (2006). Computational thinking. Retrieved from https://www.cs.cmu.edu/ 15110-s13/Wing06-ct.pdf.

Yadav, A., Mayfield, C., Zhou, N., Hambrusch, S., \& Korb, J. T. (2014). Computational thinking in elementary and secondary teacher education. ACM Transactions on Computing Education (TOCE), 14(1), 371-400.

Yecan, E., Özçınar, H., \& Tanyeri, T. (2017). Bilişim Teknolojileri öğretmenlerinin görsel programlama öğretimi deneyimleri. İlköğretim Online, 16(1), 377-393.

Y1ld1z Durak, H., \& Saritepeci, M. (2018). Analysis of the relation between computational thinking skills and various variables with the structural equation model. Computers \& Education, 116, 191-202.

Y1lmaz, G. (2012). Çokgenler konusunun ilköğretim 7. sını öğrencilerine Vee diyagramları ve zihin haritalarl kullanılarak ögretimi. Unpublished Master Dissertation, Kastamonu Univesity, Institute of Science, Kastamonu. 